\title{
Modifying the resolving cysteine affects the structure and hydrogen peroxide reactivity of peroxiredoxin 2
}

Received for publication, December 5, 2020, and in revised form, February 23, 2021 Published, Papers in Press, March 2, 2021,

https://doi.org/10.1016/j.jbc.2021.100494

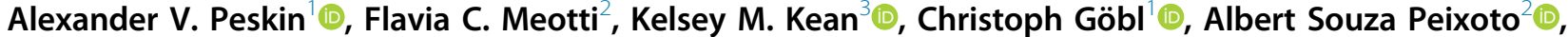 \\ Paul E. Pace ${ }^{1}$, Christopher R. Horne ${ }^{4}{ }^{-}$, Sarah G. Heath ${ }^{1}$, Jennifer M. Crowther ${ }^{4} \mathbb{B}$, Renwick C. J. Dobson ${ }^{4}$, \\ P. Andrew Karplus ${ }^{3, *}$, and Christine C. Winterbourn \\ From the ${ }^{1}$ Department of Pathology and Biomedical Science, University of Otago Christchurch, Christchurch, New Zealand; \\ ${ }^{2}$ Department of Biochemistry, Chemistry Institute, University of Sao Paulo, Sao Paulo, SP, Brazil; ${ }^{3}$ Department of Biochemistry and \\ Biophysics, Oregon State University, Corvallis, Oregon, USA; and ${ }^{4}$ School of Biological Sciences, University of Canterbury, \\ Christchurch, New Zealand
}

Edited by Ruma Banerjee

Peroxiredoxin $2(\operatorname{Prdx} 2)$ is a thiol peroxidase with an active site Cys (C52) that reacts rapidly with $\mathrm{H}_{2} \mathrm{O}_{2}$ and other peroxides. The sulfenic acid product condenses with the resolving Cys (C172) to form a disulfide which is recycled by thioredoxin or GSH via mixed disulfide intermediates or undergoes hyperoxidation to the sulfinic acid. $\mathrm{C} 172$ lies near the $\mathrm{C}$ terminus, outside the active site. It is not established whether structural changes in this region, such as mixed disulfide formation, affect $\mathrm{H}_{2} \mathrm{O}_{2}$ reactivity. To investigate, we designed mutants to cause minimal (C172S) or substantial (C172D and C172W) structural disruption. Stopped flow kinetics and mass spectrometry showed that mutation to Ser had minimal effect on rates of oxidation and hyperoxidation, whereas Asp and Trp decreased both by $\sim 100$-fold. To relate to structural changes, we solved the crystal structures of reduced WT and C172S Prdx2. The WT structure is highly similar to that of the published hyperoxidized form. C172S is closely related but more flexible and as demonstrated by size exclusion chromatography and analytical ultracentrifugation, a weaker decamer. Size exclusion chromatography and analytical ultracentrifugation showed that the $\mathrm{C} 172 \mathrm{D}$ and $\mathrm{C} 172 \mathrm{~W}$ mutants are also weaker decamers than WT, and small-angle X-ray scattering analysis indicated greater flexibility with partially unstructured regions consistent with $\mathrm{C}$-terminal unfolding. We propose that these structural changes around $\mathrm{C} 172$ negatively impact the active site geometry to decrease reactivity with $\mathrm{H}_{2} \mathrm{O}_{2}$. This is relevant for Prdx turnover as intermediate mixed disulfides with $\mathrm{C} 172$ would also be disruptive and could potentially react with peroxides before resolution is complete.

Human peroxiredoxin $2(\operatorname{Prdx} 2)$ is a cytoplasmic thiol peroxidase that is a major contributor to cellular antioxidant defense and redox regulation. It is a typical 2-Cys peroxiredoxin with an active site (peroxidatic) Cys residue $\left(C_{P}\right)$ that reacts extremely rapidly with $\mathrm{H}_{2} \mathrm{O}_{2}(1,2)$. The initial product is a

\footnotetext{
* For correspondence: Christine C. Winterbourn, christine.winterbourn@ otago.ac.nz; P. Andrew Karplus, andy.karplus@oregonstate.edu.

Present address for Kelsey M. Kean: Department of Chemistry, University of North Carolina at Chapel Hill, Chapel Hill, NC.
}

$\mathrm{C}_{P}$-sulfenic acid that undergoes a structural rearrangement to condense with the resolving Cys $\left(C_{R}\right)$ located in the C-terminal region of the opposing chain of the functional homodimer (as shown in Fig. 1). At higher $\mathrm{H}_{2} \mathrm{O}_{2}$ concentrations, this occurs in competition with further oxidation (hyperoxidation) to the sulfinic acid. During turnover, the $\mathrm{C}_{P}-\mathrm{C}_{R}$ disulfide is recycled by reaction with thioredoxin/thioredoxin reductase (Trx/TrxR). The sulfenic acid and the $\mathrm{C}_{P}-\mathrm{C}_{R}$ disulfide also react with $\mathrm{GSH}$ to form a mixed disulfide which is reduced by glutaredoxin (3).

The active site geometry dictates the exquisite specificity and high reactivity of $\mathrm{C}_{P}$ with $\mathrm{H}_{2} \mathrm{O}_{2}$ and other peroxides $(4,5)$, and it is often assumed that mutations and/or modifications of $\mathrm{C}_{R}$ would have little impact on the $\mathrm{C}_{P}$ environment and reactivity. On this basis, a number of studies, especially those investigating interacting partners or redox relays involving 2Cys peroxiredoxins, have been performed with the resolving Cys mutated to Ser or Ala (e.g., $(6,7))$. However, this assumption is not necessarily justified as, for example, the C172S variant of bacterial AhpC has a higher $\mathrm{C}_{P} \mathrm{pK}_{\mathrm{a}}$ and only $0.5 \%$ of the $\mathrm{H}_{2} \mathrm{O}_{2}$ reactivity of the WT enzyme (8). Also, the reaction of the $\mathrm{C} 173 \mathrm{~S} / \mathrm{C} 83 \mathrm{~S}$ mutant of Prdx1 with urate hydroperoxide is 10-times slower than for the WT (9). Structural studies of both the C172S (10) and C172A (11) mutants of AhpC showed that the mutations destabilized the folding of the $C$-terminal region of the protein and that because of their proximity (see Fig. $1 B$ ), this indirectly destabilized and perhaps even shifted the folding of the peroxidatic active site.

If structural disruption around $\mathrm{C}_{R}$ alters active site geometry, this could impact on peroxide reactivity during catalytic turnover. As demonstrated for Prdx2, turnover by GSH involves initial formation and reduction of a GS-Prdx disulfide (3), and resolution of the $\mathrm{C}_{P}-\mathrm{C}_{R}$ disulfide by Trx proceeds via an intermediate mixed disulfide inferred to be between $\operatorname{Trx}$ and $C_{R}$. Such mixed-disulfide derivatives of $C_{R}$ would be expected to be more structurally disruptive than a Cys to Ser or Ala mutation. Moreover, mixed disulfide formation with $\mathrm{C}_{R}$ would release reduced $\mathrm{C}_{P}-\mathrm{SH}$, which could potentially react with $\mathrm{H}_{2} \mathrm{O}_{2}$ before resolution of the conjugate. If this were the case, the mechanism of catalytic turnover of $\operatorname{Prdx} 2$ would involve steps 

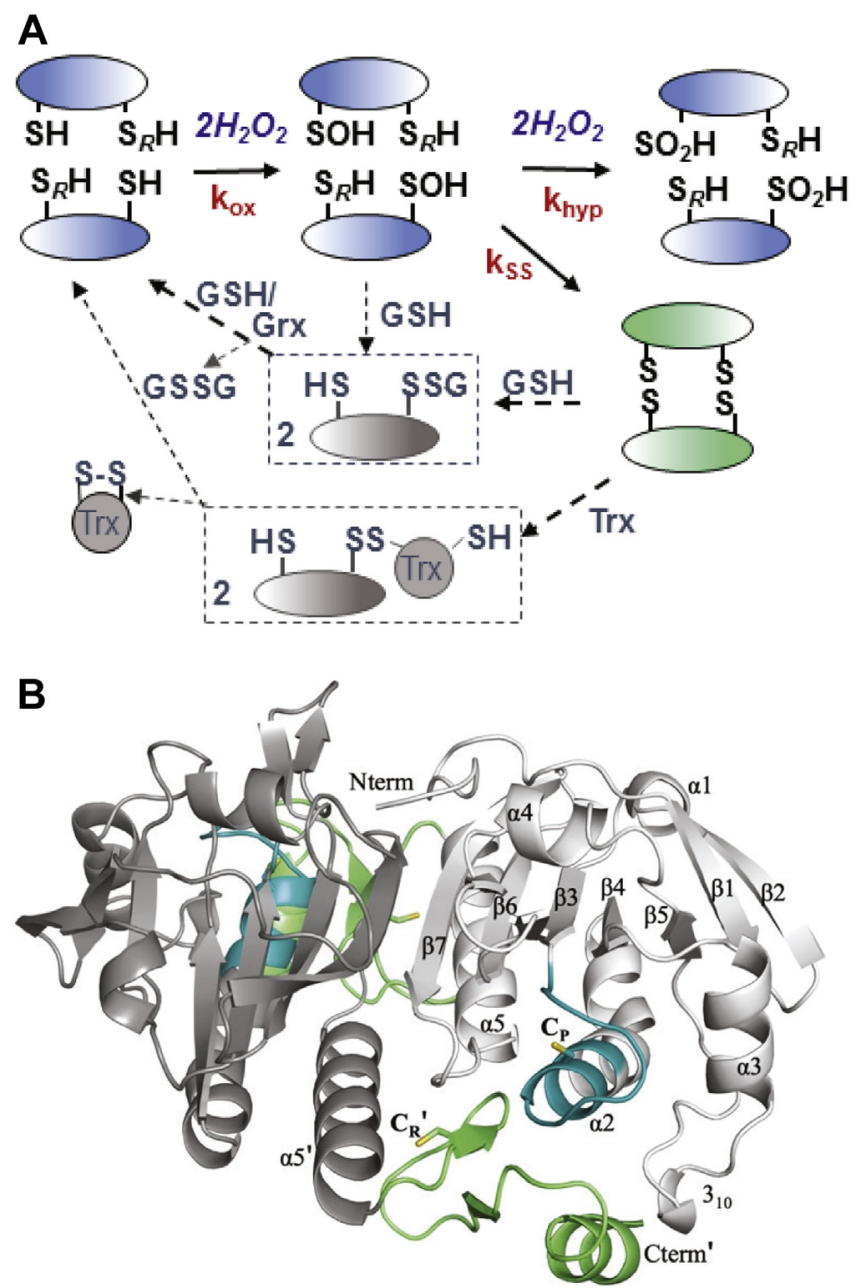

Figure 1. Oxidation and recycling of reduced Prdx2. $A$, for the WT enzyme, there is an initial fast reaction with $\mathrm{H}_{2} \mathrm{O}_{2}$ to give the sulfenic acid $\left(\mathrm{k}_{\mathrm{ox}}\right)$, then competition between interchain disulfide formation (rate constant $\mathrm{k}_{\mathrm{ss}}$ ) and hyperoxidation by additional $\mathrm{H}_{2} \mathrm{O}_{2}\left(\mathrm{k}_{\text {hyp }}\right)$. For simplicity, oxidation of the two active sites on the functional dimer is not considered separately. Blue and green represent fully folded (FF) and locally unfolded (LU) structures respectively. Recycling can proceed via reduction of the disulfide by thioredoxin (Trx) or glutathionylation of the sulfenic acid or disulfide to give mixed disulfide intermediates (represented in gray boxes) that are resolved as shown $(2,3)$. The structures and lifetimes of these intermediates are not known. The resolving Cys (C172) mutants cannot form the disulfide so the only relevant reactions with $\mathrm{H}_{2} \mathrm{O}_{2}$ are formation of the sulfenic and sulfinic acids. The FF/LU conformations of the mutants are not known. $B$, Ribbon diagram of the AB dimer (off-white and gray chains, respectively) of the human WT dithiol Prdx2 structure determined here (PDB code $7 \mathrm{KIZ}$ ). Highlighted is how the $\mathrm{C}$-terminal region of chain $\mathrm{B}$ (residues $169^{\prime}-198^{\prime}$; green) fold near the active site $C_{p}$-loop region of chain $A$ (residues $43-55$; cyan), such that the unfolding of that $C$-terminal portion influences the stability and integrity of the fully-folded $C_{P}$-loop. $C_{P}$ and $C_{R}$ ' residues side chains are shown and labeled. Prdx2, peroxiredoxin 2 .

involving mixed disulfides. To investigate the physiological relevance of these intermediates and how they affect structure and $C_{P}$ reactivity, we generated $C_{R}$ mutants designed to mimic the disruptive effect of mixed disulfide formation.

We have performed a combination of functional analysis and structural characterizations, and also report the first highresolution crystal structures of WT Prdx2 as well as the $\mathrm{C}_{\mathrm{R}}$-toserine mutation (C172S) in the reduced state. Until now the WT structure has been inferred from the original Prdx2 crystallographic study performed on the hyperoxidized form (12). The structure of the locally unfolded (LU) disulfide form has also been reported (13). For our study, we selected the commonly used $\mathrm{C} 172 \mathrm{~S}$ mutation, which is predicted to cause minimal disruption to the overall structure, and two mutants (C172D and C172W) that either through charge or bulk should be more disruptive and are therefore potential models for the effects of conjugation of $\mathrm{C}_{R}$ to Trx or GSH during Prdx recycling. We find that the modification of $\mathrm{C}_{R}$-to-Ser yields nearly identical rate constants to WT for oxidation and hyperoxidation by $\mathrm{H}_{2} \mathrm{O}_{2}$, whereas $\mathrm{C}_{\mathrm{R}}$-to-Asp and $\mathrm{C}_{R}$-to-Trp have highly decreased rates. We demonstrate that both latter mutants are largely unstructured at the $\mathrm{C}$ terminus and propose that this is how they influence $C_{P}$ reactivity. Our study highlights the important regulatory role of $\mathrm{C}_{R}$ and the C-terminal region of Prdx2 in its redox activities.

\section{Results}

Effect of $\mathrm{C}_{R}$ mutations on $\mathrm{H}_{2} \mathrm{O}_{2}$ reactivity at the Prdx2 active site

Mutation of $\mathrm{C} 172$ to Trp or Asp but not Ser decreases the reaction rate of reduced $\mathrm{Prdx} 2$ with $\mathrm{H}_{2} \mathrm{O}_{2}$

Stopped flow analysis of changes in Trp fluorescence was used to determine rate constants for the reaction of the reduced Prdx mutants with $\mathrm{H}_{2} \mathrm{O}_{2}$. As described previously (9, 14-16), WT Prdx2 gave a rapid fluorescence loss attributable to oxidation of the $C_{P}$ thiol group, followed by slower recovery (Fig. 2A). This recovery is associated with disulfide formation, plus at higher $\mathrm{H}_{2} \mathrm{O}_{2}$ concentrations, hyperoxidation $(16,17)$. The $\mathrm{C}_{R}$ mutants cannot form disulfides, and the recovery phase is not expected unless there is hyperoxidation. The mutants all showed an initial drop in fluorescence (Fig. 2, B$D$ ), but the returning fluorescence was detected only with C172S. With a 2-fold excess of $\mathrm{H}_{2} \mathrm{O}_{2}$ recovery was slower for C172S than for the WT (Fig. 2B), but as expected for hyperoxidation and described in detail in (17), the rate increased with increasing $\mathrm{H}_{2} \mathrm{O}_{2}$ concentration. In contrast, the C172D (Fig. 2C) and C172W (Fig. 2D) mutants did not present this returning fluorescence even at higher $\mathrm{H}_{2} \mathrm{O}_{2}$ concentrations but showed a slow, $\mathrm{H}_{2} \mathrm{O}_{2}$ concentration-independent, continuous drop of fluorescence similar to that observed with no $\mathrm{H}_{2} \mathrm{O}_{2}$ added, which is most likely attributable to photobleaching.

Analysis of the fast phase over a range of $\mathrm{H}_{2} \mathrm{O}_{2}$ concentrations was performed for WT Prdx2 and for each mutant (as shown in inserts, Fig. 3). Second-order rate constants, determined from plots of the pseudo first-order rate constants versus $\mathrm{H}_{2} \mathrm{O}_{2}$ (Fig. 3), are shown in Table 1 . The value for WT Prdx2 is similar to other reported values using this method (16). The C172S mutant was equally reactive. However, substituting C172 with Trp or Asp decreased reactivity with $\mathrm{H}_{2} \mathrm{O}_{2}$ by at least two orders of magnitude.

\section{Mutation of C172 to Trp or Asp decreases the rate of Prdx2} hyperoxidation

We previously analyzed Prdx2 hyperoxidation by monitoring the second phase, slow increase in Trp fluorescence 

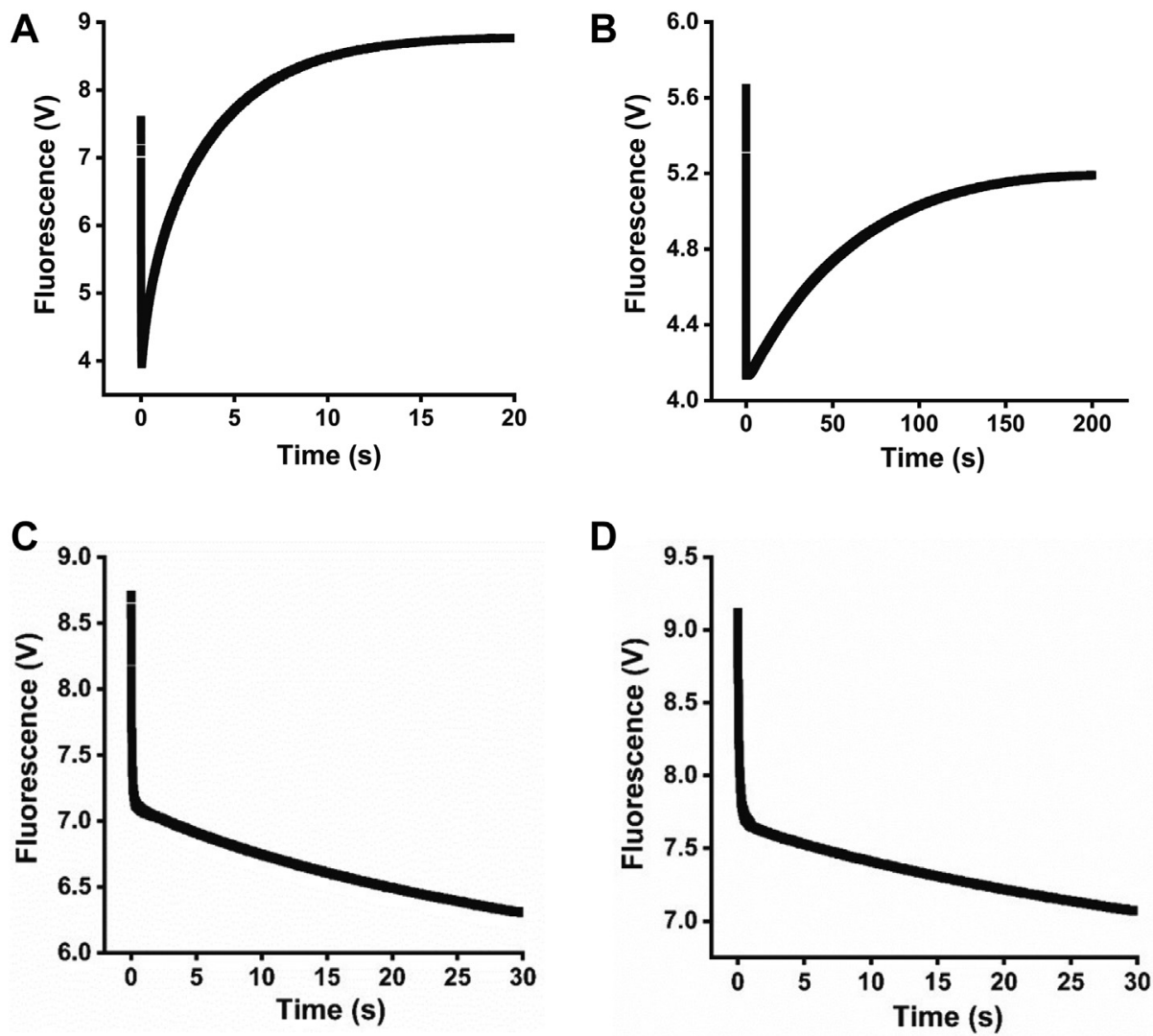

Figure 2. Prdx2 fluorescence after oxidation by $\mathbf{H}_{\mathbf{2}} \mathbf{O}_{2}$. $A$, prereduced $\operatorname{Prdx} 2 \mathrm{WT}(0.5 \mu \mathrm{M}),(B) \operatorname{Prdx} 2 \mathrm{C} 172 \mathrm{~S}(0.5 \mu \mathrm{M}),(C) \operatorname{Prdx} 2 \mathrm{C} 172 \mathrm{D}(1 \mu \mathrm{M})$, and $(D) \operatorname{Prdx2}$ $\mathrm{C} 172 \mathrm{~W}(1 \mu \mathrm{M})$ were incubated with $\mathrm{H}_{2} \mathrm{O}_{2}(1 \mu \mathrm{M}$ in $\mathrm{A}$ and $\mathrm{B}$ or $10 \mu \mathrm{M}$ in $\mathrm{C}$ and $\mathrm{D})$ in $50 \mathrm{mM}$ sodium phosphate buffer (pH 7.4; $\left.25{ }^{\circ} \mathrm{C}\right)$. Reactions were monitored over time by the variation of intrinsic protein fluorescence in the stopped-flow. MS data establishing the structures and purity of the mutants are shown in Figure S1. Prdx2, peroxiredoxin 2.

using stopped flow (as in Fig. 2, $A$ and $B$ ) (17) and by product analysis using LC/MS $(3,18)$. WT Prdx2 gave an $\left[\mathrm{H}_{2} \mathrm{O}_{2}\right]$-independent increase in fluorescence because of disulfide formation plus an $\left[\mathrm{H}_{2} \mathrm{O}_{2}\right]$-dependent component because of hyperoxidation of the sulfenic acid (Fig. 2A). Analysis of these data, described in (17), gave a second-order rate constant ( $\mathrm{k}_{\text {hyp }}$ ) of $4200 \mathrm{M}^{-1} \mathrm{~s}^{-1}$ (Table 1 ). With the C172S mutant, only the $\left[\mathrm{H}_{2} \mathrm{O}_{2}\right]$-dependent recovery was seen, and analysis of this reaction (17) gave a similar $\mathrm{k}_{\text {hyp }}$ of $3400 \mathrm{M}^{-1} \mathrm{~s}^{-1}$. Using LC/MS to monitor sulfinic acid formation and catalase competition to determine a $k_{\text {hyp }}$, we previously obtained values of $6000 \mathrm{M}^{-1} \mathrm{~s}^{-1}$ for both WT Prdx2 and the C172S mutant $(3,18)$. These are somewhat higher but in general agreement with those obtained by stopped flow.

For the $\mathrm{C} 172 \mathrm{D}$ and $\mathrm{C} 172 \mathrm{~W}$ mutants, no $\left[\mathrm{H}_{2} \mathrm{O}_{2}\right]$-dependent recovery phase was seen over the same time scale (Fig. 2, $C$ and $D$ ), indicating that mutation of C172 to Asp or Trp dramatically decreases the rate of $\operatorname{Prdx} 2$ hyperoxidation. To measure the rate directly, we carried out LC/MS analysis to follow accumulation of the sulfinic acid over time. As shown in Figure 4, this occurred over several minutes. Under these conditions, oxidation of the reduced Prdx to the sulfenic acid is relatively rapid, the rate determining step is the subsequent slower oxidation to the sulfinic acid, and the rate constant measured is $k_{\text {hyp }}$. As shown for the C172D mutant, the rate of oxidation increased with $\mathrm{H}_{2} \mathrm{O}_{2}$ concentration (Fig. $4 A$ ), and a plot of pseudo first-order rate constant versus $\mathrm{H}_{2} \mathrm{O}_{2}$ concentration (Fig. $4 B$ ) gave a second-order rate constant, $\mathrm{k}_{\text {hyp }}$ of $24 \mathrm{M}^{-1} \mathrm{~s}^{-1}$. The reaction of $\mathrm{C} 172 \mathrm{~W}$ with $\mathrm{H}_{2} \mathrm{O}_{2}$ followed a similar time course to that of the C172D mutant (Fig. 4C) and gave a similar second-order rate constant of $33 \mathrm{M}^{-1} \mathrm{~s}^{-1}$ (Table 1).

It was not possible to use the same approach to obtain a rate constant for the C172S mutant, as even with $10 \mu \mathrm{M} \mathrm{H}_{2} \mathrm{O}_{2}$, LC/ MS showed that all the protein was hyperoxidized within $20 \mathrm{~s}$. This is consistent with the $k_{\text {hyp }}$ values obtained from stopped flow and catalase competition. Thus, our results establish that the mutation of $C_{R}$ to Ser has little effect, but replacement with Trp or Asp decreases the hyperoxidation rate constant by more than 100 -fold.

To demonstrate that the reaction of the sulfenic acid with $\mathrm{H}_{2} \mathrm{O}_{2}$ is the rate determining step, we also followed the reaction with the C172D and C172W mutants by trapping the sulfenic acid with N-ethylmaleimide (NEM) (instead of reducing before analysis as in Fig. 4). With this method, MS analysis of the untreated proteins showed major peaks corresponding to the addition of 1, 2, and 3 NEM (Fig. 5, $A$ and $D$ ). At $25 \mathrm{~s}$ after addition of $\mathrm{H}_{2} \mathrm{O}_{2}(\mathrm{~B}, \mathrm{D})$, these were replaced with peaks with an additional $16 \mathrm{Da}$. This is consistent with partial alkylation of the two Cys residues present in the mutants plus 

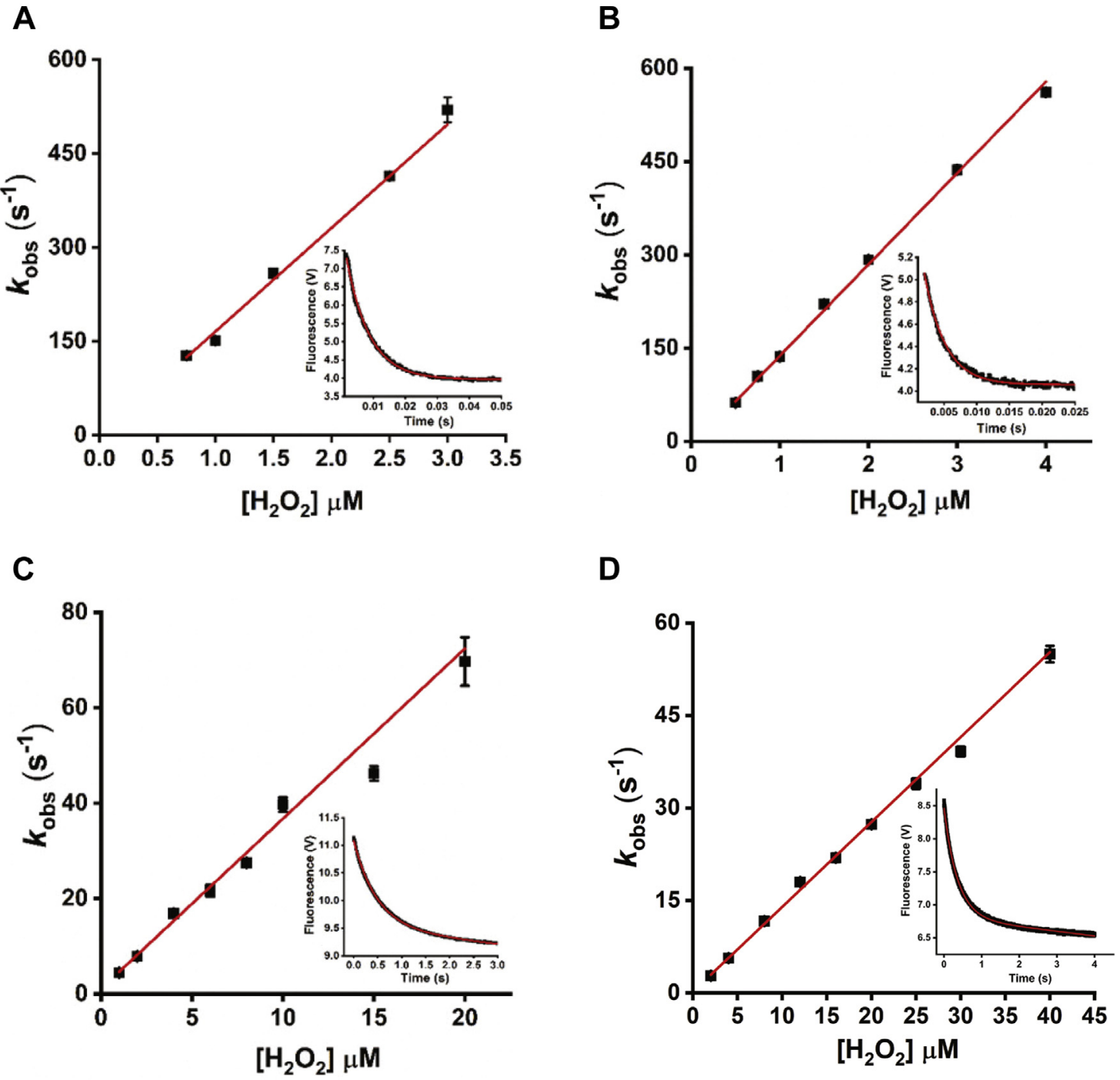

Figure 3. Kinetics of the oxidation of $\operatorname{Prdx2}$ by $\mathbf{H}_{2} \mathbf{O}_{2}$. A, prereduced Prdx2 WT (0.5 $\left.\mu \mathrm{M}\right),(B) \operatorname{Prdx2} \mathrm{C} 172 \mathrm{~S}(0.5 \mu \mathrm{M}),(C) \operatorname{Prdx2} \mathrm{C} 172 \mathrm{D}(1 \mu \mathrm{M})$, and $(D) \operatorname{Prdx2}$ $\mathrm{C} 172 \mathrm{~W}(1 \mu \mathrm{M})$ were incubated with various concentrations of $\mathrm{H}_{2} \mathrm{O}_{2}$ and monitored over time in the stopped-flow as in Figure 2 . The $k_{\text {obs }}$ of the first rapid phase of the reaction is plotted against $\mathrm{H}_{2} \mathrm{O}_{2}$ concentration and the second-order rate constants (given in Table 1) calculated from the slope. The $\mathrm{k}_{o b s}$ for each $\mathrm{H}_{2} \mathrm{O}_{2}$ concentration was calculated by fitting the experimental fluorescence decay (inset) as a single exponential for the Prdx2 WT and Prdx2 C172S mutant $(A, B)$ or as a single exponential plus linear decay for the slower Prdx2 C172D and Prdx2 C172W mutants $(C, D)$. Data are representative from two independent experiments. V, voltage; Prdx2, peroxiredoxin 2.

an additional non-Cys site, with the $16 \mathrm{Da}$ (one oxygen) corresponding to conversion of one Cys residue to a sulfenic acid and derivatization by NEM. At $150 \mathrm{~s}(\mathrm{C}, \mathrm{F})$, these peaks had declined and were replaced by peaks with one less NEM and an additional $32 \mathrm{Da}$, as expected for conversion of the sulfenic to the sulfinic acid. These results support a mechanism in which the sulfenic acid is formed and decays slowly on reaction with $\mathrm{H}_{2} \mathrm{O}_{2}$.

\section{Structural effects of $C_{R}$ mutations}

\section{$X$-ray crystal structures of reduced WT and C172S mutant of $\operatorname{Prd} \times 2$}

Recombinant $\operatorname{Prdx} 2\left(\operatorname{Prdx} 2_{\mathrm{SH}}\right)$ and the $\mathrm{C} 172 \mathrm{~S}$ variant $\left(\operatorname{Prdx} 2_{\mathrm{C} 172 \mathrm{~S}}\right)$ crystallized under the same conditions, and their structures were solved at $1.7 \AA$ and $2.15 \AA$ resolution, respectively (Table 2). As the $\operatorname{Prdx} 2_{\mathrm{SH}}$ crystals were catalytically active, we also produced the hyperoxidized sulfinate form in crystallo using a $\mathrm{H}_{2} \mathrm{O}_{2}$ soak (see Experimental procedures; Fig. S2) and solved the structure $\left(\operatorname{Prdx} 2 \mathrm{SO}_{\mathrm{SO}}\right)$ at $2.3 \AA$ resolution (Table 2). Extensive efforts to crystallize the C172D and $\mathrm{C} 172 \mathrm{~W}$ variants were not successful. The three solved structures all include a decamer (Chains A through J) in the asymmetric unit of the crystal, and all residues (Ala2-Asn198) were modeled for each chain. All subunits adopt the fully folded (FF) conformation, shown as a ribbon diagram for $\operatorname{Prdx} 2_{\mathrm{SH}}$ in Figure $1 B$ and have unambiguous electron density for the $C_{P}$ and $C_{R}$ thiols in $\operatorname{Prdx} 2_{\mathrm{SH}}$, the $C_{P}$ sulfinate in $\operatorname{Prdx} 2_{\mathrm{SO} 2}$, and the Ser172 side chain in $\operatorname{Prdx} 2_{\mathrm{C} 172 \mathrm{~S}}$ (Fig. 6). Also, all of the structures are highly similar to each other (rmsd $<0.3 \AA$ ) and to that originally published (12) for the sulfinate form of the natural enzyme (Fig. $6 E$ ). The close 
Table 1

Rate constants determined for oxidation and hyperoxidation of WT and mutants of Prdx2

\begin{tabular}{lcc}
\hline Prdx2 & $\mathbf{k}_{\mathbf{o x}}\left(\mathbf{M}^{\mathbf{- 1}} \mathbf{s}^{\mathbf{- 1}}\right)$ & $\mathbf{k}_{\mathbf{h y p}}\left(\mathbf{M}^{\mathbf{- 1}} \mathbf{s}^{\mathbf{- 1}}\right)$ \\
\hline WT & $(1.3 \pm 0.3) \times 10^{8}$ & $4200(6000)$ \\
C172S & $(1.1 \pm 0.4) \times 10^{8}$ & $3400(6000)$ \\
C172D & $(2.3 \pm 1.2) \times 10^{6}$ & $24 \pm 3$ \\
C172W & $(1.35 \pm 0.05) \times 10^{6}$ & 33 \\
\hline
\end{tabular}

$\operatorname{Prdx} 2$, peroxiredoxin 2 .

Values of $k_{o x}$ were determined from the stopped flow data in Figure 3. Analyses were performed in duplicate, and means and ranges are shown. Values of $\mathrm{k}_{\text {hyp }}$ for WT and C172S were determined by stopped flow and are taken from (17). Those in parenthesis were determined by catalase competition $(3,18)$. The value for C172D is from Figure $4 B$ (slope $+\mathrm{SE}$ ) and for $\mathrm{C} 172 \mathrm{~W}$ from the single analysis in Figure 4.

alignment of all these structures confirms the long held assumption that for this enzyme, the $\mathrm{C}_{P}$ sulfinate form mimics the functional FF active site (12).

\section{Structural impact of mutating the resolving Cys to Ser}

These structures provided a basis for assessing the impact of the $\mathrm{C} 172 \mathrm{~S}$ mutation on protein structure and dynamics. While a Ser side chain is nominally isosteric with a Cys side chain, the hydroxyl is both smaller and much more polar than the thiol, meaning it can fit in smaller spaces and requires a polar, hydrogen-bonding environment for stability. As seen in the $\operatorname{Prdx} 2_{\mathrm{C} 172 \mathrm{~S}}$ structure, the Ser172 side chain adopts a different $\mathrm{X}_{1}$ side chain rotamer so it does not sit in the fully hydrophobic pocket in which the Cys172 thiol resides (Figs. 6D and S3). Instead, it is inserted into a tightly packed position in which it can form one hydrogen bond with a buried water molecule and make additional weak polar interactions with nearby backbone amides involved in $\beta$-sheet hydrogen-bonding polar interactions. The ability of the Ser side chain to adopt a conformation that allows it to donate a hydrogen bond and have a weakly polar environment mitigates what would have been a major destabilizing factor if it was oriented into the pocket filled by the Cys172 side chain and had no hydrogen bonding partners at all. According to a MolProbity analysis (19), the Ser172 hydroxyl does not clash with neighboring atoms (not shown). The loss of hydrophobic driving force related to the burial of Cys172-SG and the small cavity left at its position would be expected to be destabilizing (e.g., $(20,21)$ ), but fulfilling the full hydrogen-bonding potential of a buried water would provide some stabilization.

Because all of the chains of the $\operatorname{Prdx} 2_{\mathrm{C} 172 \mathrm{~S}}$ structure remain in the FF form, we sought evidence of more subtle impacts on stability by looking at the mobility of the chains as seen in crystallographic B-factors. For instance, in studies of the bacterial Prdx AhpC, changes in B-factors gave evidence that the AhpC $\mathrm{C}_{P}$-to-Ser mutant stabilized the FF form (e.g., (11)), and mutants disrupting the decamer-building interface destabilized the FF form (e.g., (22)). Because of the juxtaposition of the folded $C$ terminus of one chain with the active site of the partner chain in the dimer (see Fig. $1 B$ ), we looked for coordinated increases or decreases in the B-factors of the relevant regions in the two chains. Interestingly, for the one chain in the decamer (chain I) that has no crystal packing interactions involving the C-terminal region (Fig. S4), there are both a notable increase in $\mathrm{B}$-factors of the $\mathrm{C}$-terminal region and a corresponding increase in B-factors of the active site loop in the partner subunit (chain J) of the dimer (Fig. 7). This relationship, although less marked, is also apparent for other partner subunits (Fig. S4). From this, we conclude that the C172S mutation imparts slight destabilization to the overall Prdx2 structure.

\section{Size-exclusion chromatography and analytical}

ultracentrifugation show reduced forms of the $C 172$ mutants form less stable decamers

When analyzed by size-exclusion chromatography (SEC) under reducing conditions (Fig. 8), WT Prdx2, at $\sim 0.2 \mathrm{mg} / \mathrm{ml}$ $(10 \mu \mathrm{M})$, eluted as a single peak in the decamer position. This contrasts with the disulfide form of the protein (top panel) which, as expected $(23,24)$, was about $40 \%$ dissociated into a slower moving (dimer) species. The C172S, C172D, and C172W mutants (Fig. 8, bottom three panels) were all partially dissociated (60, 45 and $62 \%$ decamer, respectively) to two
A

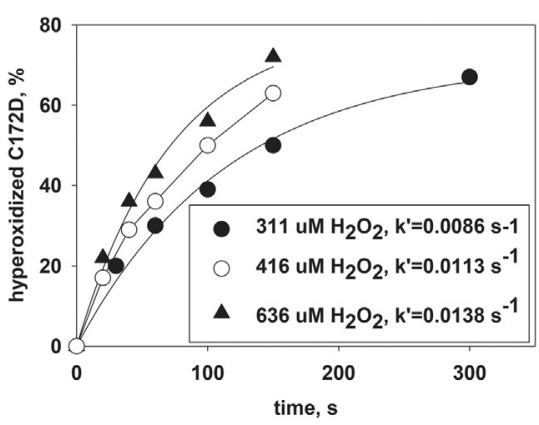

B

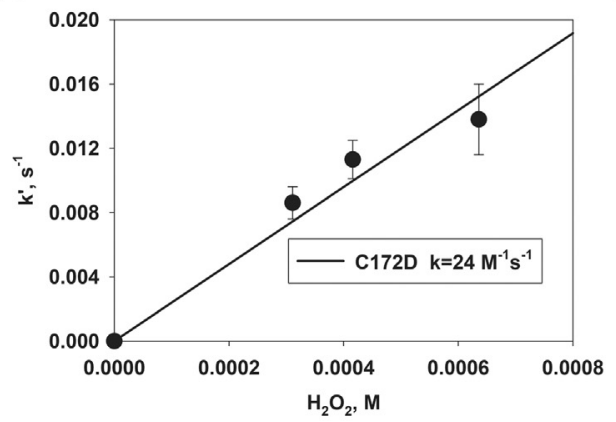

C

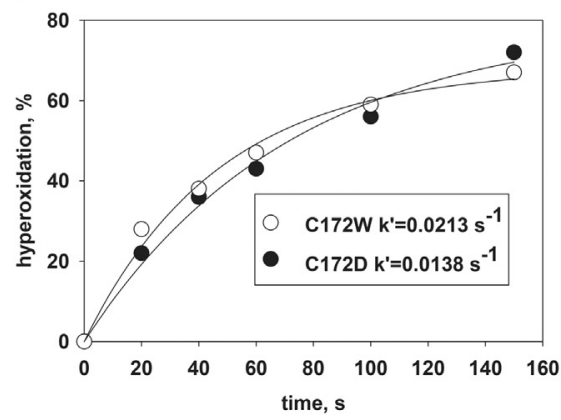

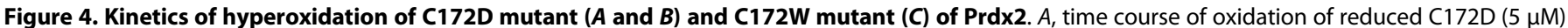

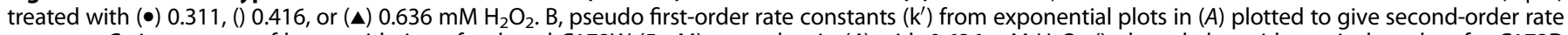

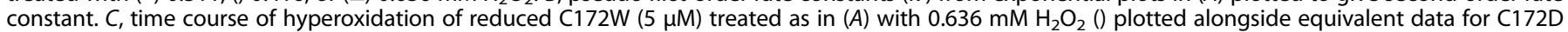

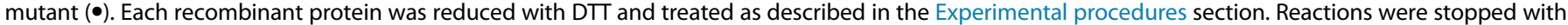

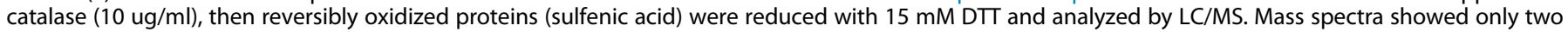

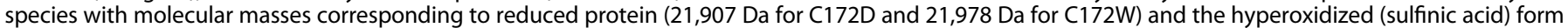
with an additional $32 \mathrm{Da}$. Prdx2, peroxiredoxin 2 


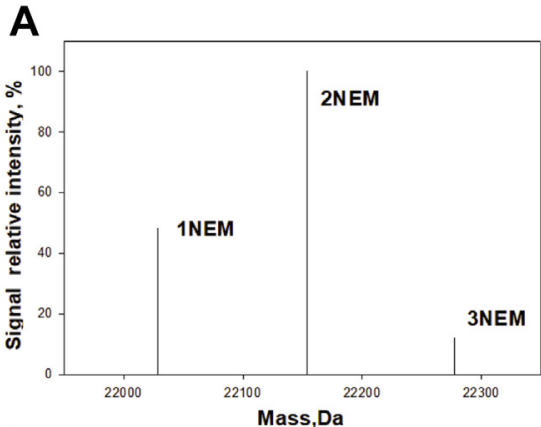

D

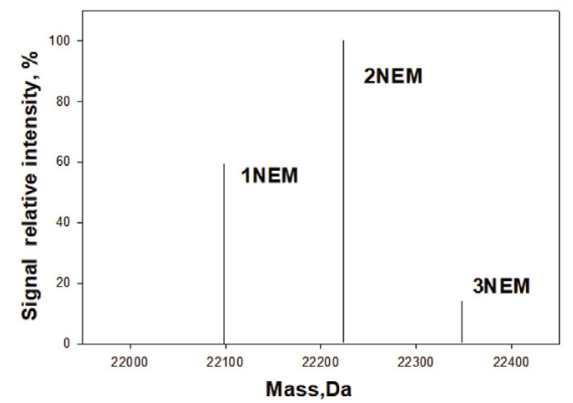

B

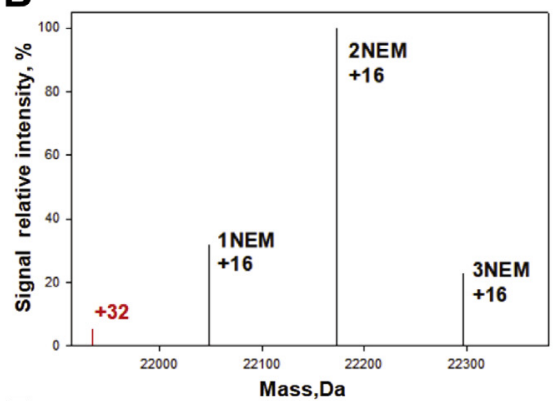

$\mathbf{E}$

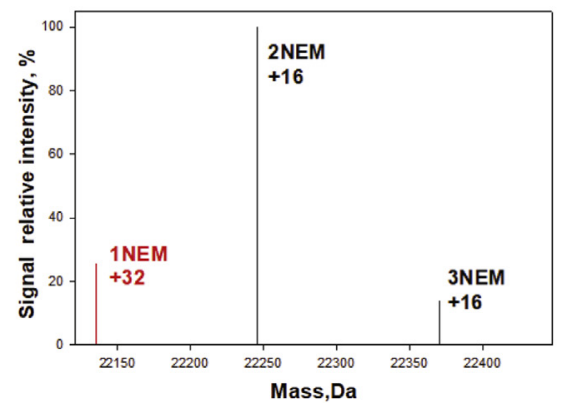

C

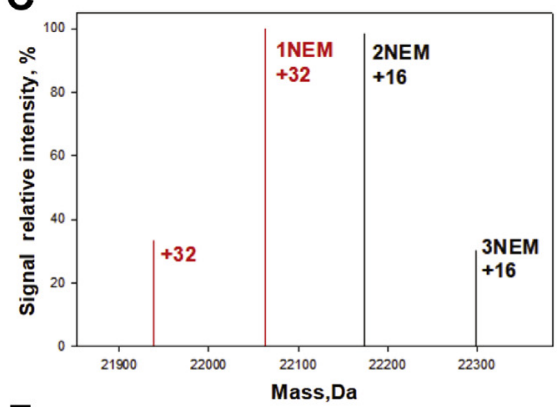

$\mathbf{F}$

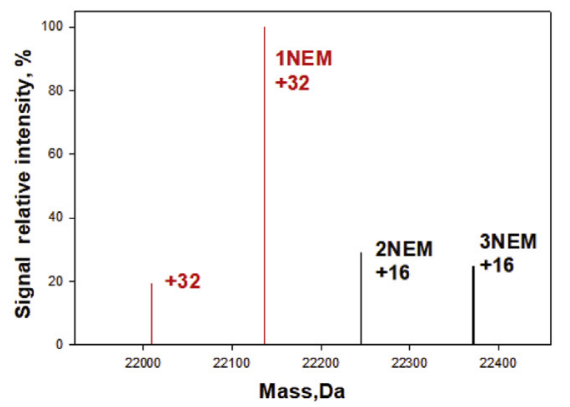

Figure 5. Formation and further oxidation of the sulfenic acid of Prdx2 C172D $(\boldsymbol{A}-\boldsymbol{C})$ and $\mathbf{C} 172 \mathrm{~W}(\boldsymbol{D}-\boldsymbol{F}) \operatorname{Prdx2}$ mutants. Reduced proteins $(5 \mu \mathrm{M})$ were treated with catalase $(10 \mu \mathrm{g} / \mathrm{ml})$ followed immediately by NEM $(20 \mathrm{mM})$ either directly $(A, D)$ or after incubation with $300 \mu M \mathrm{H}_{2} \mathrm{O}_{2}(\mathrm{as}$ in Fig. 4$)$ for $25 \mathrm{~s}(B, C)$ or $150 \mathrm{~s}(E, F)$, and samples were analyzed by LC/MS. The untreated proteins (underivatized masses 21,907 Da for C172D and 21,978 Da for C172W) show peaks corresponding to addition of 1, 2, \&3 NEM (each +125 Da). The NEM+16 Da peaks correspond to conversion of one thiol to the sulfenic acid, which is derivatized by NEM (46). The +32 Da peaks correspond to the sulfinic acid with replacement of one NEM with $O$ and are shown in red. Note that variable alkylation of Prdx2 by NEM has been observed previously and can be attributed to relatively slow derivatization of the Cys residues of this protein as well as some additional alkylation of amino groups $(3,35)$. For molecular masses of untreted proteins see Figure S1. NEM, N-ethylmaleimide; Prdx2, peroxiredoxin 2.

later-eluting peaks, the main one eluting after the WT disulfide and the other just before. These positions were highly reproducible, and tiny amounts of both can be seen in the trace for the WT protein. The prominent peak with the longest retention time is most likely the reduced dimer with structural differences compared with the WT disulfide affecting its

Table 2

Data collection and refinement statistics

\begin{tabular}{|c|c|c|c|}
\hline & $\operatorname{Prdx} 2_{\mathrm{SH}}$ & $\operatorname{Prdx} 2_{\mathrm{SO} 2}{ }^{a}$ & $\operatorname{Prdx} 2_{\mathrm{C} 172 \mathrm{~S}}$ \\
\hline \multicolumn{4}{|l|}{ Data statistics $^{\mathrm{b}}$} \\
\hline Space group & $\mathrm{C} 2$ & $\mathrm{C} 2$ & $\mathrm{C} 2$ \\
\hline Wavelength $(\AA)$ & 1.0 & 0.976 & 1.0 \\
\hline Unit cell: a, b, c $(\AA) ; \beta\left(^{\circ}\right)$ & $229.8,88.1,127.1 ; 100.0$ & $231.0,88.0,125.6 ; 100.2$ & $233.2,88.3,125.2 ; 99.2$ \\
\hline Resolution $(\AA)$ & $49.7-1.70(1.74-1.70)$ & $49.6-2.29(2.35-2.29)$ & $35.2-2.15(2.21-2.15)$ \\
\hline Unique reflections & $271,919(19,847)$ & $109,799(8119)$ & $136,298(10,028)$ \\
\hline Multiplicity & $6.7(6.4)$ & $22.5(21.6)$ & $5.0(4.7)$ \\
\hline Average $\mathrm{I} / \sigma$ & $8.9(0.6)$ & $10.6(0.9)$ & $7.5(0.7)$ \\
\hline $\mathrm{R}_{\text {meas }}(\%)$ & $11.6(303)$ & $46.1(533)^{\mathrm{c}}$ & $25.2(283)$ \\
\hline Completeness (\%) & $99.3(98.5)$ & $97.9(98.8)$ & $99.8(99.9)$ \\
\hline \multirow{2}{*}{\multicolumn{4}{|c|}{ Refinement statistics }} \\
\hline & & & \\
\hline Amino acid residues & 1970 & 1970 & 1970 \\
\hline Solvent atoms & 1689 & 1738 & 1753 \\
\hline Non-H atoms & 17,587 & 17,669 & 17,662 \\
\hline RMS bonds $(\AA)$ & 0.011 & 0.002 & 0.002 \\
\hline RMS angles () & 1.0 & 0.6 & 0.5 \\
\hline$\varphi, \psi$ favored $(\%)^{d}$ & 97 & 97 & 97 \\
\hline$\varphi, \psi$ outliers (\%) ${ }^{d}$ & 0.2 & 0.4 & 0.3 \\
\hline$<B_{\text {protein }}>\left(\AA^{2}\right)$ & 42 & 50 & 50 \\
\hline$<\mathrm{B}_{\text {solvent }}>\left(\AA^{2}\right)$ & 54 & 54 & 55 \\
\hline $\mathrm{R}_{\text {work }}(\%)$ & 18.3 & 18.2 & 19.5 \\
\hline $\mathrm{R}_{\text {free }}(\%)$ & 22.1 & 23.3 & 23.7 \\
\hline PDB code & $7 \mathrm{KIZ}$ & $7 \mathrm{KJO}$ & $7 \mathrm{KJ} 1$ \\
\hline
\end{tabular}

Prdx2, peroxiredoxin 2 .

${ }^{a}$ Data merged from three crystals.

${ }^{b}$ Highest resolution shell in parentheses.

${ }^{c}$ In the lowest resolution bin, the $\mathrm{R}_{\text {meas }}$ value for this dataset is just $4.7 \%$; the high overall $\mathrm{R}_{\text {meas }}$ value results from the many weak high resolution reflections in the data set that thanks to the $\sim 23$-fold multiplicity have an improved signal-to-noise that is not reflected in their $\mathrm{R}_{\text {meas }}$ values (38).

${ }^{d}$ Based on Molprobity (19). 
A

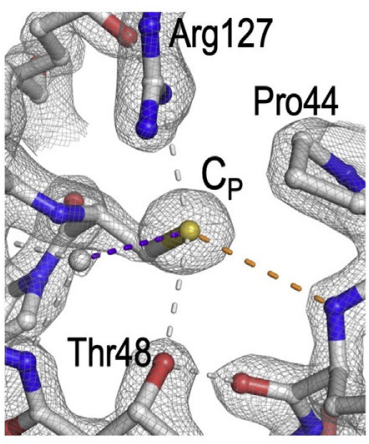

B

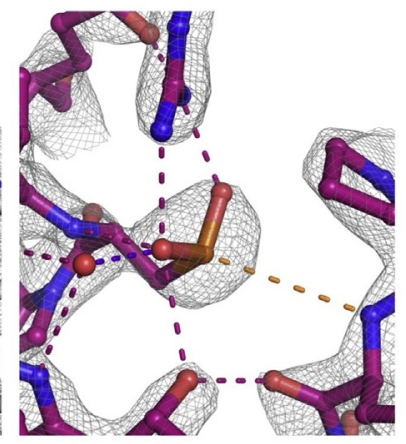

C

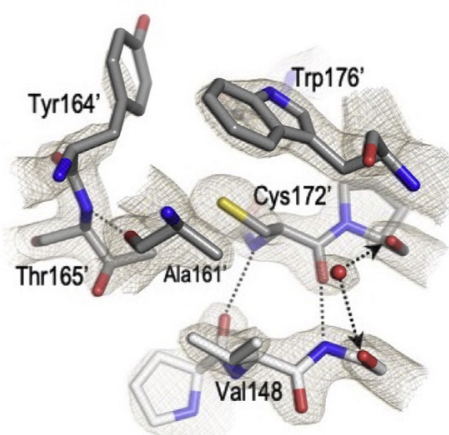

D

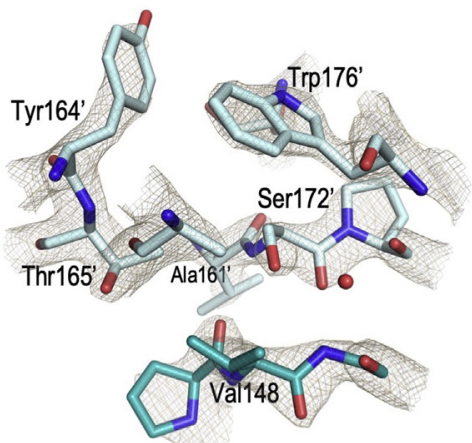

E

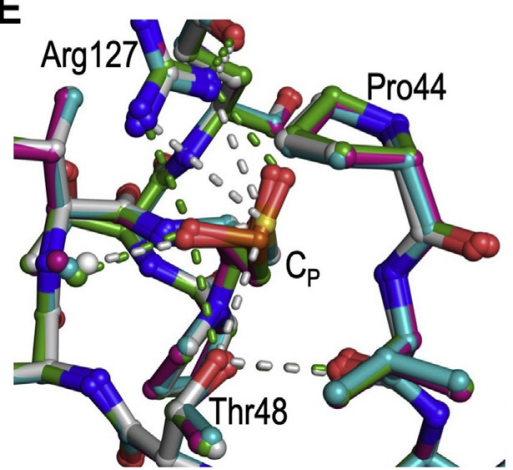

Figure 6. The peroxidatic and resolving Cys residues in the $\mathbf{P r d x} \mathbf{2}_{\mathrm{sH}}$ and $\mathbf{P r d x} \mathbf{2}_{\mathrm{sO} 2}$ and $\mathbf{P r d x} \mathbf{2}_{\mathrm{c} 172 \mathrm{~s}}$ crystal structures. $A$, electron density (contoured at $2.25 \rho_{\mathrm{rms}}$ ) shown for the Cys51 ( $\left.\mathrm{C}_{P}\right)$ thiol and surrounding atoms (off-white carbons with side chains labeled) in Prdx $2_{\mathrm{SH}} \cdot B$, as in panel $(A)$, but for the $C_{\mathrm{s}} 51$ sulfinate and surrounding atoms (magenta carbons) in $\operatorname{Prdx}_{\mathrm{so} 2}$ (see also Fig. S2). $C_{\text {, }}$ as in panel $A$, but for the Cys $172\left(C_{R}\right)$ and surrounding atoms (cream carbons from chain $A$, gray carbons and numbering denoted with' from chain $B$ ) in $\operatorname{Prdx} 2_{\mathrm{SH}} . D$, as in panel $C$, but for the Ser 172 residue (teal carbons from chain $A$, light teal carbons for chain $B$ ) in Prdx2 ${ }_{C 172 s}$. E, overlay of the Prdx2 $2_{S H}$ (off-white carbons), Prdx2 $2_{S O 2}$ (purple carbons), and Prdx2 1725 (teal carbons) active sites with PDB entry $1 \mathrm{QMV}$ (green carbons). Prdx2, peroxiredoxin 2.

mobility, and the minor one possibly the tetramer. When SEC was performed with $3 \mathrm{mg} / \mathrm{ml}$ protein (Fig. S5), the decamer increased to 62 and $76 \%$ for the C172D and C172W mutants, respectively, consistent with the species being in dynamic equilibrium. Although all protein variants eluted predominantly in the decameric region, there were small and reproducible differences in their elution volumes. Both C172D and
C172W mutants eluted earlier than the WT species, whereas C172S elution was slightly delayed. However, SEC-static light scattering analysis performed on the WT and C172W mutant confirmed that both showed the expected molecular weight of the decamer (Fig. S6). The earlier SEC elution suggests that the mutations, as well as altering the self-association equilibria and favoring dissociation, expand the structure of the decamer.

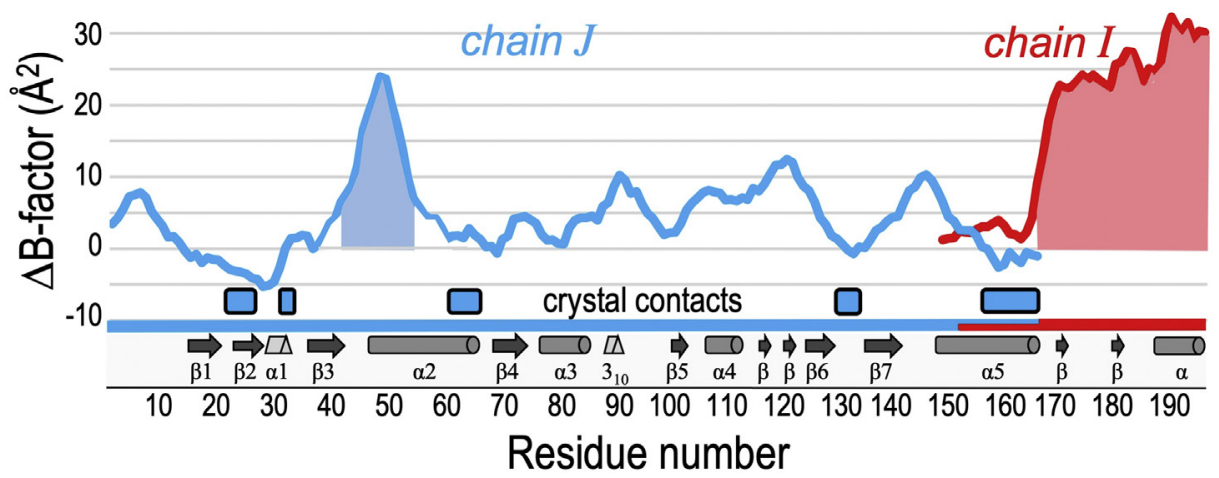

Figure 7. The C172S mutation leads to increased chain mobility for the one dimer with the relevant C-terminal and active site regions undisturbed by crystal packing interactions. The difference in backbone $\mathrm{B}$-factors ( $\operatorname{Prdx} 2_{\mathrm{C} 172 \mathrm{~S}}$ minus $\operatorname{Prdx} 2_{\mathrm{SH}}$ smoothed over a sliding 5-residue window) is shown as a function of residue number for a composite chain that includes the chain $\mathrm{J}$ (cyan curve) active site region (blue shading) and the interacting chain I (red curve) C-terminal region (pink shading). An 20-residue overlap of the two chains (representing helix 5) is included to show their consistency. Chain J regions between residue 1 and 170 making crystal packing interactions are indicated (black-edged cyan rectangles). Chain I makes no crystal contacts in the region of residues 150 through the $C$ terminus. Secondary structural elements along the chain are shown schematically. Figure S3 has further details regarding the B-factor comparisons and the crystal packing information and backbone B-factor traces for all ten chains. Prdx2, peroxiredoxin 2. 


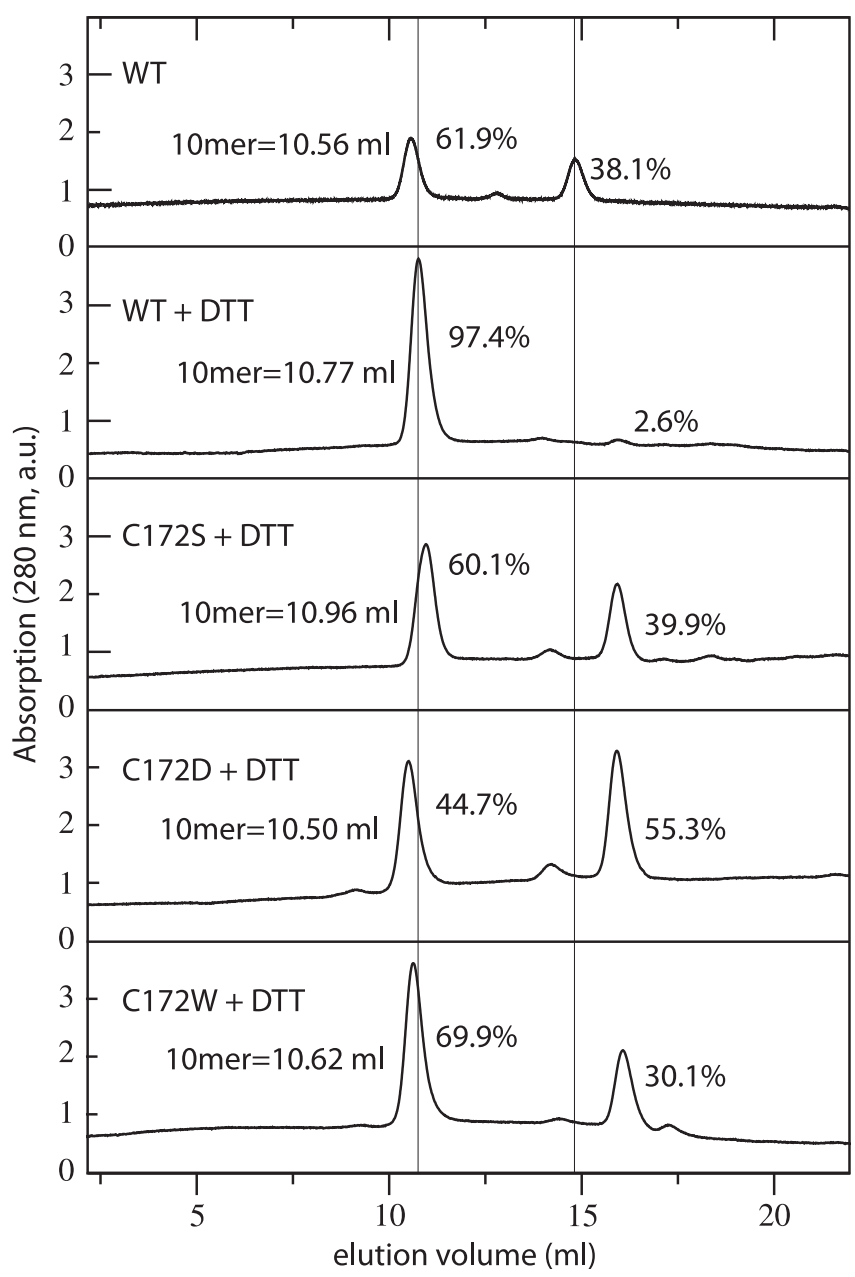

Figure 8. Size-exclusion profiles of the Prdx2 variants. The top panel shows WT Prdx2 as the disulfide, prepared, and run under nonreducing conditions. For this, the column was equilibrated and the sample run with PBS, pH 7.4. The other panels show profiles for reduced WT and mutated C172 mutants run in SEC buffer containing DTT. Analyses were performed at a concentration of $0.2 \mathrm{mg} / \mathrm{ml}(10 \mu \mathrm{M})$ as described in the Experimental procedures section. For the reduced proteins, percentages are shown for the combined 14 and $16.5 \mathrm{ml}$ peaks. The different elution times of the decameric fractions are indicated on the left. Prdx2, peroxiredoxin 2.

The subtle differences in decameric structure of the mutants were further investigated using analytical ultracentrifugation (AUC) using the sedimentation velocity method, with size distributions obtained by two-dimensional spectral analysis using UltraScan (Fig. 9). The sedimentation profile of WT Prdx2 (black trace) is consistent with a single peak at $8.66 \mathrm{~S}$ and gave a predicted molar mass of $220 \mathrm{kDa}$, which is very close to the calculated decameric mass of $219 \mathrm{kDa}$ (Table S1). In contrast, the sedimentation of all three Prdx2 mutants showed the presence of multiple species consistent with a selfassociation reaction boundary, with the distribution between decamers and smaller species consistent with the observation by SEC. The smaller species were found at 2 to $3 \mathrm{~S}$ (corresponding to molar masses between 27 and $40 \mathrm{kDa}$ ) and were not investigated further. Detailed data analysis performed on the largest detected peak showed similar sedimentation coefficients of $8.66 \mathrm{~S}$ and $8.52 \mathrm{~S}$ for the WT protein and the

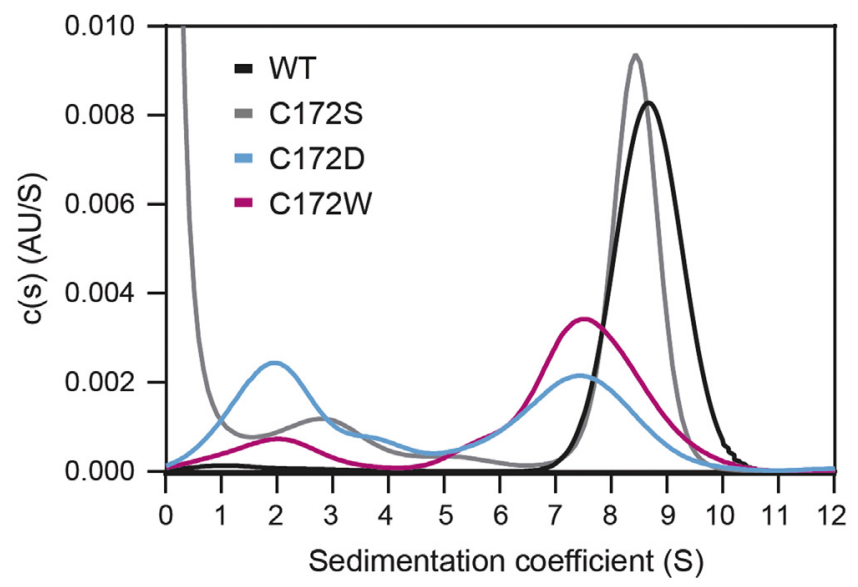

Figure 9. Sedimentation coefficient distribution determined by analytical ultracentrifugation. 2DSA-Monte Carlo model displaying the sedimentation coefficient (S) distribution of WT Prdx2 (black), C172D Prdx2 (cyan), C172S Prdx2 (gray), and C172W Prdx2 (magenta). All $\sim 0.35 \mathrm{mg} / \mathrm{ml}$ $(15 \mu \mathrm{M})$; experimental conditions are described in the Experimental procedures section. Prdx2, peroxiredoxin 2.

C172S mutant, whereas the C172D and C172W mutants had values of $7.60 \mathrm{~S}$ and $7.70 \mathrm{~S}$, respectively. The calculated molar mass of these species (Table S1) suggest that like the WT, all the mutants are decameric. The calculated frictional ratios $(f)$ $f_{0}$ ) from these data allow conclusions to be drawn about the shape of the complexes, where a perfect sphere would yield a value of 1 . In our analysis, the WT protein showed a $f / f_{0}$ value of 1.47 , and the C172S mutant a value of 1.38 , which is consistent with a prolate overall shape. In contrast, the C172D and $\mathrm{C} 172 \mathrm{~W}$ mutants yielded larger $f / f_{0}$ values of 1.67 and 1.80 , respectively, indicating that these mutants are more asymmetric and less compact than the WT and C172S proteins.

\section{Small angle $X$-ray scattering data indicate that the C172D and C172W mutants are partially unstructured}

As neither the C172D nor C172W mutant yielded crystals, we performed additional analyses on these samples in solution, as well as the WT protein, using small-angle X-ray scattering (SAXS). Analyses were performed with data from the decameric fraction (see Experimental procedures). The background-subtracted scattering curves of two different concentrations are shown in Figure 10, $A-C$, and the highquality data were used for calculation of the pair-distance distribution function (PDDF). WT Prdx2 showed a compact fold and the shape of the PDDF is similar to other barrelshaped complexes with ring-like structure (Fig. 10D). Calculation of the PDDF using the experimental WT crystal structure yields a good match to the experimental SAXS curve, indicating that highly similar conformations are present in the crystal and in solution (Figs. 10 and S7A). Using a Kratky plot to qualitatively assess the flexibility of the structure further indicates that WT Prdx2 has little structural disorder (Fig. $\mathrm{S} 7 \mathrm{~B})$. In contrast, the PDDFs of both mutants extend to larger distances, indicating a less compact average conformation in solution (Fig. 10D). The clear maxima evident in the WT sample are rather smeared out, indicating a less 
A

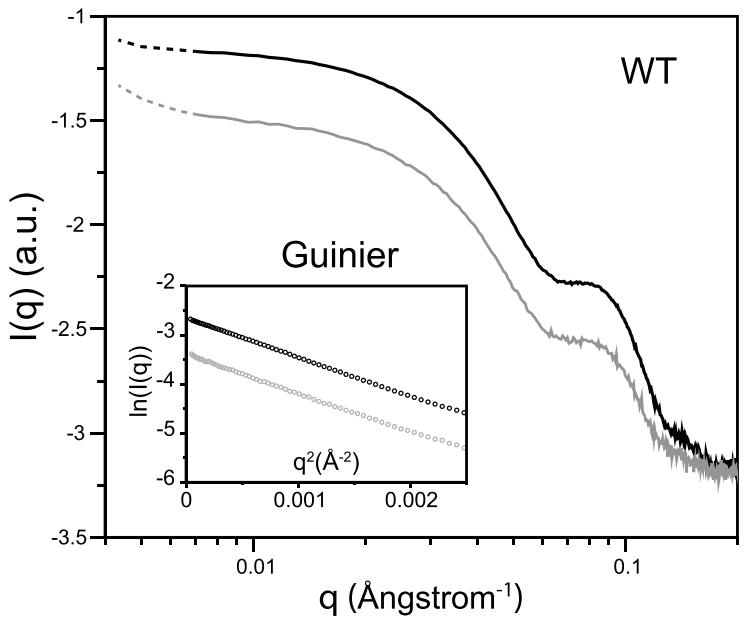

C

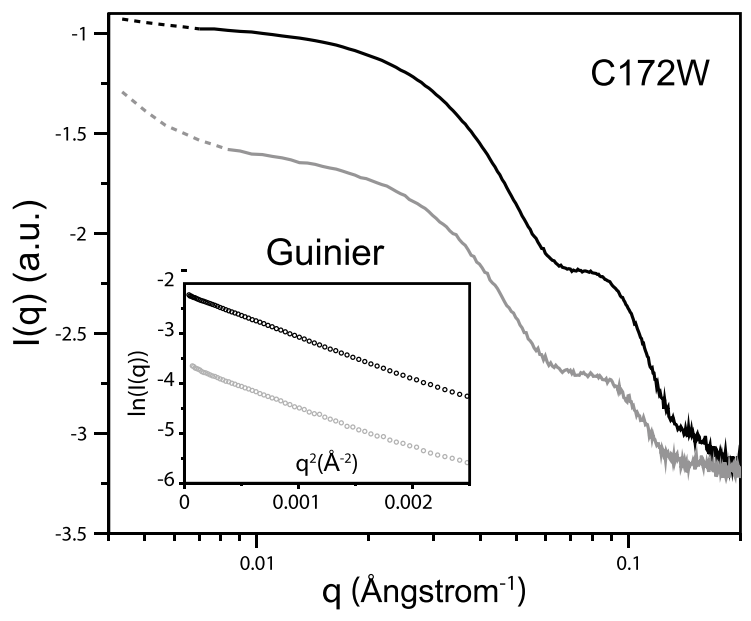

B

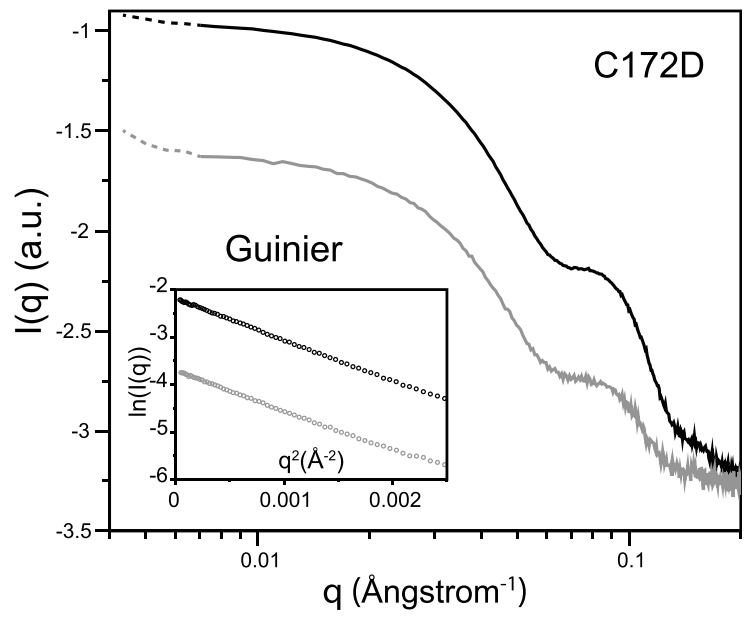

D

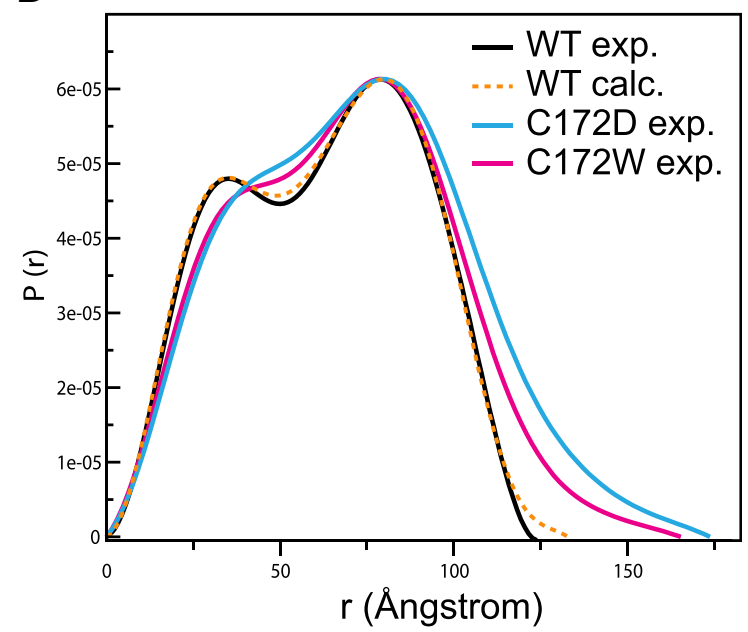

Figure 10. SAXS analysis of the Prdx2 mutants. Double logarithmic SEC-SAXS scattering curves of two concentrations of WT (A), C172D (B), and C172W (C) mutants of Prdx2 are shown. First data points were removed for analysis, as indicated by dashed lines. The inset displays the Guinier plot for low scattering angles with three to eight leading points removed, indicating the lack of substantial interparticle attraction or repulsion. $D$, the pair distance distribution functions $\mathrm{P}(\mathrm{r}$ ) of the WT (black), C172D (cyan) and C172W (magenta) decameric species shows larger structures for the two mutant samples. The orange dashed line shows the calculated function of the reduced WT Prdx2 high-resolution X-ray structure. Prdx2, peroxiredoxin 2; SAXS, small-angle X-ray scattering; SEC, size-exclusion chromatography.

well-defined barrel-like shape. Furthermore, Kratky plots imply a greater level of flexible, disordered regions, as shown in Figure S7B.

\section{Discussion}

\section{$\mathrm{H}_{2} \mathrm{O}_{2}$ reactivity}

The main aims of our study were to establish how modification and structural changes around the resolving Cys of Prdx2 affect the reactivity of the peroxidatic Cys and assess whether this has relevance for the recycling of the oxidized Prdx. We first determined how mutations of $\mathrm{C}_{R}$ affect the rates of oxidation and hyperoxidation of $\operatorname{Prdx} 2$ by $\mathrm{H}_{2} \mathrm{O}_{2}$. Consistent with our premise that substituting Cys with Ser would be minimally disruptive, we obtained rates of oxidation of the reduced form and hyperoxidation of the sulfenic acid of the C172S mutant that were indistinguishable from those of the WT. In contrast, the C172D and C172W mutations, which we expected to be more disruptive, had a major effect on $\mathrm{H}_{2} \mathrm{O}_{2}$ reactivity. Each mutation decreased the rates of oxidation and hyperoxidation by approximately 100 -fold compared with WT Prdx2. We therefore conclude that changing the charge or adding more bulk at the resolving Cys site of Prdx2 disrupts the overall Prdx2 structure sufficiently to affect the geometry of the active site and decrease the reactivity of the peroxidatic Cys with $\mathrm{H}_{2} \mathrm{O}_{2}$. The $\mathrm{C}_{P}$ and $\mathrm{C}_{R}$ regions cannot therefore be considered as structurally independent.

\section{Structural features of WT and C172S mutant}

To obtain structural information, we first performed a highresolution X-ray crystallographic analysis of reduced WT $\operatorname{Prdx} 2$, which previously has been solved only for the sulfinic acid (12) and disulfide (13) forms of the protein. We replicated the sulfinic acid structure after in situ oxidation by $\mathrm{H}_{2} \mathrm{O}_{2}$ and show that the added oxygens are accommodated with minimal change in geometry at the active site. This validates the generally held assumption that the reduced and hyperoxidized 


\section{Properties of resolving Cys mutants of Prdx2}

Prdx2 are in the FF form, and their structures are nearly identical. Furthermore, the SAXS data are fully consistent with the solution structure of the WT protein matching the conformation seen in the crystals.

For the reduced $\mathrm{C} 172 \mathrm{~S}$ mutant, the $-\mathrm{OH}$ side chain adopts an $\mathrm{H}$-bond stabilized orientation different from the $-\mathrm{SH}$, but otherwise its structure is very close to the FF form of the WT, with the active site unperturbed. This is consistent with the high reactivity with $\mathrm{H}_{2} \mathrm{O}_{2}$ being preserved. However, the crystallographic B-factors for the $\mathrm{C} 172 \mathrm{~S}$ mutant are indicative of slight destabilization. Structural differences are also evident from the solution studies, where our combined analysis using SEC and AUC indicates a weaker dimer-dimer interface and a greater propensity for the reduced decamer to dissociate. SEC analysis showed about $40 \%$ dissociation at $10 \mu \mathrm{M}$, whereas WT Prdx2 remains fully decameric at $1 \mu \mathrm{M}(23,24)$. As the decamer:dimer ratio decreases with decreasing protein concentration, the C172S mutant should be mostly dissociated at the 10-fold lower concentrations we used for the kinetic analyses. Consistent with our findings, Pastor-Flores et al. (25) investigated Prdx2 oligomerization in living cells and found evidence for dissociation of the $\mathrm{C} 172 \mathrm{~S}$ decamer under these conditions. The fact that high $\mathrm{H}_{2} \mathrm{O}_{2}$ reactivity was maintained in this mutant implies that for Prdx2, the decameric structure is not necessary for high reactivity. In contrast, others have reported that mutations that disrupt the dimer-dimer interface in the yeast Prdx, TSA1, and in bacterial AhpC result in up to 50-fold decrease in peroxide reactivity $(22,26,27)$. The extent of this effect presumably reflects how much the overall structure is altered and not just the dimer-decamer equilibrium.

The finding that the C172S mutation does not affect the peroxide reactivity of Prdx2 is useful validation for applying this mutant for mechanistic studies of cellular redox interactions of Prdx2. The same mutation in the yeast Prdx, TSA2, also had minimal effect on the crystal structure and caused only a 2-fold decrease in reactivity with $\mathrm{H}_{2} \mathrm{O}_{2}$ (7). However, the same mutation in bacterial AhpC decreased the reaction rate of $\mathrm{C}_{P}$-SH with $\mathrm{H}_{2} \mathrm{O}_{2}$ to $0.5 \%$ (8). It is possible to rationalize this difference in behavior by recognizing that the "set points" of the FF-LU equilibrium (see Fig. 9 of Perkins et al. (11)) in WT Prdx2 and AhpC are different because of an extra helix in the $\mathrm{C}$ terminus of Prdx2 making the folding of the rest of protein more stable. For AhpC, the WT protein has an FF state that is already marginally destabilized, so adding the $\mathrm{C}_{R} \rightarrow$ Ser mutation pushes it so that substantial amounts of the LU form are present; however, for Prdx2, the FF form of the WT protein is highly stabilized so that even with a destabilization caused by the C172S mutation, the FF form may still be stable enough to be the dominant form under reaction conditions.

\section{C172D and C172W structures}

For the $\mathrm{C} 172 \mathrm{D}$ and $\mathrm{C} 172 \mathrm{~W}$ mutants, their lack of ability to crystallize is consistent with disruption of folding of the Cterminal region. The solution studies including SAXS analysis are also indicative of structural disruption. There is some preservation of the decameric structure, although the dimer interface is weakened, and under our SEC conditions, both mutants were partially dissociated. Of note, the extent of dissociation is similar to that of the $\mathrm{C} 172 \mathrm{~S}$ mutant so this cannot explain their dramatic drop in $\mathrm{H}_{2} \mathrm{O}_{2}$ reactivity. However, the consistent slight shift in running characteristics of the decamer peak on SEC, and the higher frictional ratios revealed by AUC suggest a structural difference to the WT conformation. In addition, the SAXS data reveal a pair-distance distribution function that is consistent with a larger structure. The Kratky plot shows partial unfolding of the C172D and C172W mutants, whereas the WT sample shows compact characteristics and highly matches the FF crystal structure. We therefore interpret the combined data as evidence that mutation of $\mathrm{C}_{R}$ to Asp or Trp results in locally unfolding of the C-terminal region. In view of the proximity of these regions of opposing subunits (Fig. 1B), it is reasonable to infer that structural disruption extends beyond the $\mathrm{C}$ terminus to the active site and affects the alignment of $C_{P}$ and/or residues that form critical hydrogen bonds that are crucial for activating $\mathrm{H}_{2} \mathrm{O}_{2}$ and other peroxides. This would explain why these less compact mutants lead to decreased reactivity.

\section{Implications for Prdx2 turnover}

Decreased reactivity of $C_{P}$ when $C_{R}$ is derivatized has implications for the turnover of $\operatorname{Prdx} 2$. The redox cycle of $\operatorname{Prdx} 2$, and other 2Cys Prdxs, involves rapid oxidation to the sulfenic acid, rearrangement from FF to LU form, disulfide formation in competition with hyperoxidation by excess peroxide, and reduction to complete the cycle (Fig. $1 A$ ). The intermediate steps in the oxidation pathway have been well studied $(18,28$, 29), but the reduction mechanism is less characterized. Reduction by Trx/TrxR or by GSH/Grx initially involves formation of a mixed disulfide intermediate with either the reactive thiol (C32) of Trx or with GSH (Fig. 1A). If the mixed disulfide were with $C_{R}$, then $C_{P}$ would be released as its reduced form. The crystal structures of the WT and C172S mutants clearly show that there is no room to add bulk to the C172 side chain, so mixed disulfides must disrupt the structure of the C-terminal region. Based on the effects of the C172W and $\mathrm{C} 172 \mathrm{D}$ mutations, this should decrease rates of both oxidation and hyperoxidation. Therefore, if the mixed disulfide intermediates were sufficiently long lived, $\mathrm{H}_{2} \mathrm{O}_{2}$ could oxidize $\mathrm{C}_{P}$ before the resolution step was complete, and the peroxidatic cycle could proceed without the Prdx becoming fully reduced. Turnover could be slower, and hyperoxidation less evident.

This mechanism provides a possible explanation for previous observations of glutathionylation (3). GSH forms mixed disulfides with Prdx2, by reacting with the sulfenic acid and by exchange with the disulfide (3). Both $C_{P}$ and $C_{R}$ can be glutathionylated, with rapid exchange between the two and slow resolution of the mixed disulfides. When reduced $\operatorname{Prdx} 2$ is treated with high $\mathrm{H}_{2} \mathrm{O}_{2}$ so that most becomes hyperoxidized, GSH competes for the sulfenic acid but is only partially protective. However, when Prdx2 disulfide is treated with GSH 
and high $\mathrm{H}_{2} \mathrm{O}_{2}$, most of the Prdx2 becomes diglutathionylated, and there is very little hyperoxidation (3). In this case, initial disulfide exchange to give a mixed disulfide is followed by oxidation of the released $\mathrm{C}_{P}$-SH to the sulfenic acid, which preferentially reacts with GSH rather than undergoing hyperoxidation. These observations could be explained by the sulfenic acid having lower reactivity with $\mathrm{H}_{2} \mathrm{O}_{2}$ when $\mathrm{C}_{R}$ is glutathionylated.

Based on kinetic data on the relative rates of hyperoxidation and condensation, the possibility of a mixed disulfide with Trx reacting with $\mathrm{H}_{2} \mathrm{O}_{2}$ during $\mathrm{Prdx} 2$ turnover also warrants consideration. These rates have been assessed either by treating reduced Prdx2 with stoichiometric concentrations $\mathrm{H}_{2} \mathrm{O}_{2}$ or by measuring inactivation during turnover of the enzyme in a peroxidase assay with $\operatorname{Trx} / \operatorname{TrxR}$ and NADPH. Three studies measured the ratio of rate constants $k_{\text {hyp }} / k_{s s}$ using the first approach, either by monitoring Trp fluorescence with stopped flow $(16,17)$ or by MS analysis $(18)$ and obtained ratios of (7-16) $\times 10^{3} \mathrm{M}^{-1}$. Progressive inactivation due to hyperoxidation during turnover has been followed by several groups. Bolduc et al. (13) used the method of Nelson et al. (30) to determine the $\mathrm{H}_{2} \mathrm{O}_{2}$ concentration that gives $1 \%$ inactivation at each cycle of disulfide formation $\left(\mathrm{C}_{\mathrm{hyp} 1 \%}\right)$. They obtained a value of $\sim 5 \mu \mathrm{M}$, which translates to a $\mathrm{k}_{\text {hyp }} / \mathrm{k}_{\mathrm{ss}}$ ratio of $\sim 2000 \mathrm{M}^{-1}$. Other reports show kinetic traces with little inactivation over 100 cycles with $0.25 \mathrm{mM} \mathrm{H}_{2} \mathrm{O}_{2}$ (pH 7.4) (31) or $1 \mathrm{mM} \mathrm{H}_{2} \mathrm{O}_{2}$ (pH 7.0) (32), implying an even lower ratio. Thus, there is a suggestion of less inactivation during turnover, but more direct studies are needed to establish if this is the case.

The actual mechanism of Prdx2 turnover under different conditions will depend on the kinetics of oxidation and reduction of the different intermediates in the cycle. Producing pure forms of conjugates between $\mathrm{C}_{R}$ and $\mathrm{Trx}$ or GSH is challenging because of the multitude of exchange and resolution reactions possible. We propose that the C172D and C172W mutants to some extent mimic the mixed disulfides, in which case we infer that mixed disulfide formation would destabilize the FF active site and decrease the peroxide reactivity of $C_{P}$. However, further information on the lifetime and reactivity of the mixed disulfides is needed to assess their impact on the function of Prdx2 and potentially other Prdxs.

\section{Experimental procedures}

\section{Constructs and recombinant WT and mutant Prdx2 proteins}

The pET28a-His-Prdx2 construct, which has been described previously (33), encodes N-terminally His-tagged human $\operatorname{Prdx} 2$ with a linker sequence of 30 amino acids. Mutagenesis reactions to create resolving cysteine substitutions $(\mathrm{C} 172 \mathrm{D}$ and C172W) were made as described previously (33) on the same WT His-Prdx2 template, using the following oligonucleotides: C172D forward, 5' - CTGGTCCAAGCTTTCCAGT ACACAGACGAGCATGGGGAAGTTGATCCCGCTGGCTG3'; C172D reverse, 5' - CAGCCAGCGGGATCAACTTCC CCATGCTCGTCTGTGTACTGGAAAGCTTGGACCAG-3'; C172W forward, 5'- CTGGTCCAAGCTTTCCAGTAC ACAGACGAGCATGGGGAAGTTTGGCCCGCTGGCTG-3';
C172W reverse, 5' - CAGCCAGCGGGCCAAACTTCCC CATGCTCGTCTGTGTACTGGAAAGCTTGGACCAG-3'.

Successful mutagenesis was confirmed using introduced restriction sites and sequencing, and constructs were transformed into competent BL21 codon+ Escherichia coli (Stratagene) for protein expression and purification. The C172S mutant was generated as previously (3), and His-Prdx2 WT and mutants were expressed according to reported methods $(33,34)$. Proteins were isolated from $E$. coli in the absence of dithiothreitol (DTT) and the His tag and linker sequences were cleaved off with Factor Xa protease (Roche). Protein concentrations were measured using Direct Detect (Merck-Millipore), and preparations were aliquoted in $20 \mathrm{mM}$ 4-(2-hydroxyethyl)1-piperazineethanesulfonic acid (Hepes) pH 7.5, $100 \mathrm{mM} \mathrm{NaCl}$ and stored at $-80{ }^{\circ} \mathrm{C}$.

Mass spectrometry analysis showed the purified WT Prdx2 to be in its disulfide form, and the C172 mutants to be predominantly glutathionylated $(\mathrm{M}+305)$ as previously reported for C172S, (3). On SDS-PAGE, each mutant ran as a single monomeric band in a similar position to WT. The recombinant proteins were reduced by DTT before experiments, with excess DTT removed using Micro Bio-Spin 6 columns (Bio$\operatorname{Rad})$ as described $(3,35)$. LC/MS of the reduced proteins gave molecular masses of 21,881 Da for C172S, 21,906 Da for C172D, and 21,976 Da for C172W, which is consistent with disulfide reduction and removal of the GSH, and the theoretical protein masses of 21,876 $\mathrm{Da}, 21,904 \mathrm{Da}$, and 21,975 $\mathrm{Da}$, respectively (Fig. S1).

\section{Kinetics of Prdx oxidation by $\mathrm{H}_{2} \mathrm{O}_{2}$ using stopped-flow}

Prdx2 oxidation was followed by monitoring intrinsic fluorescence changes $(9,14,15)$. Prereduced proteins $(0.5 \mu \mathrm{M}$ WT Prdx2 with $\sim 2.5 \mu \mathrm{mol} \mathrm{SH} / \mu \mathrm{mol}$ protein or $\mathrm{C} 172 \mathrm{~S}$ Prdx2 with $\sim 1.5 \mu \mathrm{mol} \mathrm{SH} / \mu \mathrm{mol}$ protein; one $\mu \mathrm{M}$ C172D or C172W Prdx2 with $\sim 1.5 \mu \mathrm{mol} \mathrm{SH} / \mu \mathrm{mol}$ protein) were mixed with increasing concentrations of $\mathrm{H}_{2} \mathrm{O}_{2}$ in a stopped-flow instrument (Applied Photophysics SX20MV), excitation $\Lambda 280 \mathrm{~nm}$, emission above $\Lambda 340 \mathrm{~nm}$. The reactions were performed at $25^{\circ} \mathrm{C}$ in $50 \mathrm{mM}$ sodium phosphate buffer $\mathrm{pH} \quad 7.4$ containing $0.1 \mathrm{mM}$ diethylenetriaminepenta-acetic acid. Buffer solutions were pretreated with $10 \mu \mathrm{g} / \mathrm{ml}$ catalase to remove any trace $\mathrm{H}_{2} \mathrm{O}_{2}$ (35). An excess of $\mathrm{H}_{2} \mathrm{O}_{2}$ was used for pseudo first-order conditions. Observed rate constants $\left(k_{\text {obs }}\right)$ for fluorescence decrease were determined by fitting data to single exponential equations for the fastest enzymes (WT and C172S Prdx2) and to single exponential plus linear equation for C172D and C172W Prdx2. The fittings were set from 2 to $50 \mathrm{~ms}$. The values of $k_{\text {obs }}$ obtained from the decreasing fluorescence were plotted against $\mathrm{H}_{2} \mathrm{O}_{2}$ concentrations, and the corresponding second-order rate constants were determined from the slope of these linear fittings.

\section{Time course of hyperoxidation of the C172D and C172W mutants}

Proteins $(5 \mu \mathrm{M})$ were incubated at room temperature with stated concentrations of $\mathrm{H}_{2} \mathrm{O}_{2}$ in $20 \mathrm{mM}$ sodium phosphate 


\section{Properties of resolving Cys mutants of Prdx2}

buffer, pH 7.4 containing $0.1 \mathrm{mM}$ diethylenetriaminepentaacetic acid. Aliquots were taken at intervals, the reaction was terminated by adding $10 \mu \mathrm{g} / \mathrm{ml}$ catalase and $10 \mathrm{mM}$ DTT to reduce reversible oxidation products. Samples were analyzed by LC/MS for reduced Prdx2 and accumulation of $+32 \mathrm{Da}$ adduct. In some experiments, reactions were stopped with $10 \mathrm{mM}$ N-ethylmaleimide (NEM) to block the sulfenic acid plus any residual thiol, and LC/MS analysis was performed for the derivatized sulfenic acid plus hyperoxidized products.

\section{LC/MS analysis}

Samples containing $0.5 \mu \mathrm{g}$ protein were injected onto an Accucore-150-C4 $(50 \times 2.1-\mathrm{mm}, 2.6-\mu \mathrm{m})$ column $\left(60^{\circ} \mathrm{C}\right)$ using a Dionex Ultimate 3000 HPLC system coupled to a Velos Pro mass spectrometer (Thermo Scientific) as described previously (3). The entire protein peak was deconvoluted and protein species corresponding to more than $5 \%$ of the total quantified. For NEM-derivatized samples, peaks corresponding to addition of varying numbers of NEM were observed. These have been combined for quantification of each particular species.

\section{X-ray crystallography}

Recombinant Prdx2 WT at $14.5 \mathrm{mg} / \mathrm{ml}$ in storage buffer with $9 \mathrm{mM}$ DTT was crystallized at $4{ }^{\circ} \mathrm{C}$ in hanging drops using a reservoir solution of $0.1 \mathrm{M}$ Tris $\mathrm{pH} 8.5$ and 25\% PEG 3350 and $0.2 \mathrm{M}$ salt. For the crystals yielding the dithiol Prdx2 $\left(\operatorname{Prdx} 2_{\mathrm{SH}}\right)$ data, the salt was ammonium sulfate; and for the crystals used to generate the hyperoxidized Prdx2 structure $\left(\operatorname{Prdx} 2_{\mathrm{SO} 2}\right)$ structure, as well as for the $\mathrm{C} 172 \mathrm{~S}$ variant $\left(\operatorname{Prdx} 2_{\mathrm{C} 172 \mathrm{~S}}\right)$, the salt was magnesium chloride. For data collection, all crystals were passed through artificial mother liquor containing $20 \%$ glycerol as cryoprotectant and then mounted in a loop and frozen by plunging into liquid nitrogen. For generating the $\mathrm{Prdx} 22_{\mathrm{SO} 2}$ crystals, the artificial mother liquor also contained $10 \mathrm{mM} \mathrm{H}_{2} \mathrm{O}_{2}$, and crystals were soaked for varying times up to $\sim 5$ min before being frozen.

Data were collected at beamline 5.0.2 with $\lambda=1.0 \AA$ $\left(\operatorname{Prdx} 2_{\mathrm{SH}}\right.$ and $\left.\operatorname{Prdx} 2_{\mathrm{C} 172 \mathrm{~S}}\right)$ and beamline 5.0.3 with $\lambda=0.98 \AA$ $\left(\operatorname{Prdx} 2_{\mathrm{SO} 2}\right)$ at the Advanced Light Source. A full $360^{\circ}$ of data were collected for $\operatorname{Prdx} 2_{\mathrm{SH}}\left(0.25 \mathrm{~s}, \Delta \varphi=0.25^{\circ}\right.$ exposures) with a detector distance of $225 \mathrm{~mm}$ and for $\operatorname{Prdx} 2_{\mathrm{C} 172 \mathrm{~S}}(0.5 \mathrm{~s}, \Delta \varphi=$ $0.5^{\circ}$ exposures) with the detector at $300 \mathrm{~mm}$. For $\operatorname{Prdx} 2_{\mathrm{SO} 2}$, data were merged from three crystals (all with $1 \mathrm{~s}, \Delta \varphi=1^{\circ}$ exposures) using detector distances of 300,250 , or $260 \mathrm{~mm}$ for crystals soaked about $45 \mathrm{~s}, 90 \mathrm{~s}$, and $5 \mathrm{~min}$, respectively. Among multiple data sets collected for peroxide-soaked crystals (ranging from $3 \mathrm{~s}$ to $5 \mathrm{~min}$ ), these three data sets yielded electron densities showing that $\mathrm{C}_{P}-\mathrm{SO}_{2}$ had been formed (Fig. S2), and so, they were merged to provide a single improved data set for analysis. Although we tried to capture the $\mathrm{C}_{P}$-SOH form, we were not successful. Images were processed using XDS (36) and the CCP4 program suite (37). For $\operatorname{Prdx} 2_{\mathrm{C} 172 \mathrm{~S}}$, substantial decay was apparent in the latter images, and only the first 525 images were included in the final data reduction. In all cases, a $\mathrm{CC}_{1 / 2}$ of $\sim 0.2$ was used to define the resolution cutoff (38), and the same $5 \%$ of reflections, randomly selected from the $\operatorname{Prdx} 2_{\mathrm{SH}}$ data set were marked for cross-validation.

The structure of $\operatorname{Prdx} 2_{\mathrm{SH}}$, with one decamer in the asymmetric unit, was solved by molecular replacement using Phenix (39), using the decamer of hyperoxidized human Prdx2 (PDB code 1QMV; $100 \%$ sequence identity) as the search model. All manual model building was done in Coot (40). Refinements were carried out using Phenix (39) with riding hydrogens. Electron density for the $\mathrm{N}$ termini is ill-formed and has been interpreted as a mixture of two alternate conformations although even with this model uninterpreted density remains. Based on mass spectrometry, we know that the purified protein starts with Ala-2, so we have not included Met- 1 in the model. For the $1.7 \AA$ resolution Prdx $2_{\mathrm{SH}}$ structure, TLS refinement was done using one group for each of the ten chains in the asymmetric unit along with their associated waters (i.e., ten total TLS groups). The isomorphous structures of $\operatorname{Prdx} 2_{\mathrm{C} 172 \mathrm{~S}}$ and $\operatorname{Prdx} 2_{\mathrm{SO} 2}$ were built starting from a near-final refined model of $\operatorname{Prdx} 2_{\mathrm{SH}}$, and these structures were refined using individual isotropic B-factors. Data collection and refinement statistics are in Table 2.

\section{Size exclusion chromatography}

SEC was performed with an AKTA chromatography system using a Superdex 200 Increase 10/300 Gl column operated at $4{ }^{\circ} \mathrm{C}$ (both Cytiva). Frozen stock samples $(\sim 5 \mathrm{mg} / \mathrm{ml})$ were thawed on ice, diluted to $10 \mu \mathrm{M}(\sim 0.2 \mathrm{mg} / \mathrm{ml})$, and incubated with $10 \mathrm{mM}$ DTT for $30 \mathrm{~min}$. Samples $(100 \mu \mathrm{l})$ were injected using a $500 \mu \mathrm{l}$ loop, and runs were performed with $0.5 \mathrm{ml} / \mathrm{min}$ flow rate using a degassed running buffer consisting of $20 \mathrm{mM}$ Hepes, $100 \mathrm{mM} \mathrm{NaCl}$, freshly added $10 \mathrm{mM}$ DTT, adjusted to $\mathrm{pH}$ 7.4, by addition from a stock solution of $4 \mathrm{M} \mathrm{NaOH}$ (SEC buffer). Identical experiments were also performed at $3.0 \mathrm{mg} /$ $\mathrm{ml}$ protein concentration. For integration, peak areas were defined manually and calculated by using Unicorn 7.1 (Cytiva).

For molecular mass determination of the decameric species using SEC-static light scattering, reduced WT and C172W mutant were separated as above, except at room temperature with a flow rate of $0.4 \mathrm{ml} / \mathrm{min}$ and the column connected to a Viscotek 302 to 040 Triple Detector PGC/SEC system (Malvern). Molecular weights were calculated from the acquired refractive index, right-angle, and low-angle light scattering data using Omnisec 4.7.0. For calibration, a $3 \mathrm{mg} / \mathrm{ml}$ solution of bovine serum albumin (AlbuMAX I, Gibco) was run under the same conditions.

\section{Small-angle X-ray scattering}

SAXS data were acquired at the Australian Synchrotron on the SAXS/WAXS beamline equipped with a PILATUS $1 \mathrm{M}$ detector $(170 \times 170 \mathrm{~mm}$, effective pixel size $172 \times 172 \mu \mathrm{m})$. The $\mathrm{X}$-ray wavelength provided was $1.0332 \AA$, and the sample detector distance was set at $2700 \mathrm{~mm}$, which produced a $q$ range of 0.006 to $0.4 \AA-1$. Protein samples were thawed on ice and incubated with $10 \mathrm{mM}$ TCEP (Bond-Breaker, Thermo Scientific) for $30 \mathrm{~min}$. Data were collected during two independent measurements, first with WT and C172W concentrations of $7.0 \mathrm{mg} / \mathrm{ml}$ and a C172D concentration of $4.4 \mathrm{mg} / \mathrm{ml}$ and the 
second measurement using the same concentrations and a 1:1 dilution. Data merging indicated that the highest concentration was of good quality, and a single high concentration curve has been used for further analysis. Samples were injected onto an online Superdex 200 5/150 Gl column (Cytiva) equilibrated with SEC running buffer (see above) at $0.45 \mathrm{ml} / \mathrm{min}$. The scattering data were detected during the course of protein elution using exposures of $1 \mathrm{~s}$ in a $1.0 \mathrm{~mm}$ glass capillary at 12 ${ }^{\circ} \mathrm{C}$. The scattering data were processed using ScatterBrain IDL 2.822 (Australian Synchrotron Facility) to apply data reduction, integration of individual frames, and conversion to onedimensional data. Further data analysis has been performed using the ATSAS 3.0.2 package (41).

\section{Analytical ultracentrifugation}

The reduced forms of WT Prdx2 and the mutants were analyzed by AUC using the sedimentation velocity method. For all but the C172S mutant, SEC was performed as above, and the decamer elution peak was pooled and concentrated to $0.35 \mathrm{mg} / \mathrm{ml}$ using Amicon Ultra-15 Centrifugal Filter Units with $30 \mathrm{kDa}$ molecular weight cut-off. SEC and AUC were performed on the same day. The C172S mutant was analyzed at the same concentration without prior SEC. Sedimentation velocity experiments were performed in an XL-I analytical ultracentrifuge (Beckman Coulter) using double sector sapphire cells and epon charcoal centre-pieces in an An-50 Ti 8hole rotor. Data were obtained at 45,000 rpm using $380 \mu \mathrm{l}$ Prdx2 solution and $400 \mu \mathrm{l}$ of buffer (20 mM Hepes, $100 \mathrm{mM}$ $\mathrm{NaCl}, 10 \mathrm{mM}$ TCEP, $\mathrm{pH}$ 7.4) as the reference. Data were collected at $20{ }^{\circ} \mathrm{C}$ using radial absorbance scans at $285 \mathrm{~nm}$ and step size of $0.003 \mathrm{~cm}$ and analyzed using UltraScan 4.0 (42). Data were evaluated by 2DSA (43), followed by 50 MonteCarlo interactions providing 95\% confidence intervals for all measured parameters (44). The data were further analyzed using the enhanced van-Holde/Weischet method in UltraScan-III. All fitting procedures were performed on the UltraScan LIMS cluster. The buffer viscosity (1.026 cp), buffer density $(1.0039 \mathrm{~g} / \mathrm{ml})$, and an estimate of the partial specific volume for each protein sample based on the amino acid sequence was determined using UltraScan-III (WT: 0.7380; C172S: 0.7381; C172D: 0.7378; and C172W: 0.7386) (45).

\section{Materials}

All biochemicals were from Sigma unless stated otherwise.

\section{Data availability}

Coordinates and structure factors for $\operatorname{Prdx} 2_{\mathrm{SH}}, \operatorname{Prdx} 2_{\mathrm{SO} 2}$ and Prdx $2_{\mathrm{C} 172 \mathrm{~S}}$ have been deposited in the Protein Data Bank with accession numbers $7 \mathrm{KIZ}, 7 \mathrm{KJ} 0$, and $7 \mathrm{KJ} 1$, respectively.

Supporting information-This article contains supporting information (42).

Acknowledgments-We are grateful to Andreas Königstorfer and Alysiya Lytvyn for assistance with the recombinant protein purification. Some parts of the work were performed at the SAXS/WAXS and MX2 beamlines of the Australian Synchrotron, part of the Australian Nuclear Science and Technology Organisation, making use of the ACRF Detector at the MX2 beamline and we are grateful to Tim Ryan and Nigel Kirby for performing the measurements.

Author contributions-C. C. W., A. V. P., and P. A. K. designed the study. A. V. P. carried out the kinetic experiments with MS analysis. F. C. M. with A. S. P. carried out the stopped flow experiments. K. M. K. carried out the X-ray crystallography under the guidance. P. A. K. and P. E. P. produced the mutant proteins. C. G. with C. R. H. and S. G. H. carried out and analyzed the SEC and SAXS experiments. J. M. C. and R. C. J. D. carried out the AUC experiments. C. C. W. was responsible for preparing the manuscript with contributions from P. A. K., F. C. M., C. G., and A. V. P. Others provided comments on the manuscript.

Funding and additional information-This work was supported by the Marsden Fund of New Zealand (C. C. W., A. V. P., P. E. P.); by the US National Institutes of Health (grant R01-GM119227 to P. A. K. and K12-GM000678 to K. M. K.); by a Sir Charles Hercus Fellowship from the Health Research Council of New Zealand (C. G.), the Fundação de Amparo à Pesquisa do Estado de São Paulo (FAPESP) projects: CEPID-Redoxoma 2013/07937-8, Young Investigator 2018/14898-2 and multi-user equipment 2015/10411-3 grants (Brazil, FM). The Advanced Light Source is supported by the Director, Office of Science, Office of Basic Energy Sciences, of the US Department of Energy under Contract No. DE-AC0205CH11231. The content is solely the responsibility of the authors and does not necessarily represent the official views of the National Institutes of Health.

Conflict of interest-The authors declare that they have no conflicts of interest with the contents of this article.

Abbreviations - The abbreviations used are: AUC, analytical ultracentrifugation; $\mathrm{C}_{P}$, peroxidatic cysteine; $\mathrm{C}_{R}$, resolving cysteine; $\mathrm{FF}$, fully folded; LU, locally unfolded; Prdx, peroxiredoxin; SAXS, small angle X-Ray scattering; SEC, size exclusion chromatography; Trx, thioredoxin; TrxR, thioredoxin reductase.

\section{References}

1. Rhee, S. G., and Kil, I. S. (2017) Multiple functions and regulation of mammalian peroxiredoxins. Annu. Rev. Biochem. 86, 749-775

2. Perkins, A., Nelson, K. J., Parsonage, D., Poole, L. B., and Karplus, P. A. (2015) Peroxiredoxins: Guardians against oxidative stress and modulators of peroxide signaling. Trends Biochem. Sci. 40, 435-445

3. Peskin, A. V., Pace, P. E., Behring, J. B., Paton, L. N., Soethoudt, M., Bachschmid, M. M., and Winterbourn, C. C. (2016) Glutathionylation of the active site cysteines of peroxiredoxin 2 and recycling by glutaredoxin. J. Biol. Chem. 291, 3053-3062

4. Perkins, A., Parsonage, D., Nelson, K. J., Ogba, O. M., Cheong, P. H., Poole, L. B., and Karplus, P. A. (2016) Peroxiredoxin catalysis at atomic resolution. Structure 24, 1668-1678

5. Hall, A., Nelson, K., Poole, L. B., and Karplus, P. A. (2011) Structure-based insights into the catalytic power and conformational dexterity of peroxiredoxins. Antioxid. Redox Signal. 15, 795-815

6. Kwak, M. S., Kim, H. S., Lkhamsuren, K., Kim, Y. H., Han, M. G., Shin, J. M., Park, I. H., Rhee, W. J., Lee, S. K., Rhee, S. G., and Shin, J. S. (2019) Peroxiredoxin-mediated disulfide bond formation is required for nucleocytoplasmic translocation and secretion of HMGB1 in response to inflammatory stimuli. Redox Biol. 24, 101203 
7. Anschau, V., Ferrer-Sueta, G., Aleixo-Silva, R. L., Bannitz Fernandes, R., Tairum, C. A., Tonoli, C. C. C., Murakami, M. T., de Oliveira, M. A., and Netto, L. E. S. (2020) Reduction of sulfenic acids by ascorbate in proteins, connecting thiol-dependent to alternative redox pathways. Free Radic. Biol. Med. 156, 207-216

8. Nelson, K. J., Perkins, A., Van Swearingen, A. E. D., Hartman, S., Brereton, A. E., Parsonage, D., Salsbury, F. R., Jr., Karplus, P. A., and Poole, L. B. (2018) Experimentally dissecting the origins of peroxiredoxin catalysis. Antioxid. Redox Signal 28, 521-536

9. Carvalho, L. A. C., Truzzi, D. R., Fallani, T. S., Alves, S. V., Toledo, J. C., Jr., Augusto, O., Netto, L. E. S., and Meotti, F. C. (2017) Urate hydroperoxide oxidizes human peroxiredoxin 1 and peroxiredoxin 2. J. Biol. Chem. 292, 8705-8715

10. Nelson, K. J., Parsonage, D., Hall, A., Karplus, P. A., and Poole, L. B. (2008) Cysteine pK(a) values for the bacterial peroxiredoxin AhpC. Biochemistry 47, 12860-12868

11. Perkins, A., Nelson, K. J., Williams, J. R., Parsonage, D., Poole, L. B., and Karplus, P. A. (2013) The sensitive balance between the fully folded and locally unfolded conformations of a model peroxiredoxin. Biochemistry $52,8708-8721$

12. Schroder, E., Littlechild, J. A., Lebedev, A. A., Errington, N., Vagin, A. A., and Isupov, M. N. (2000) Crystal structure of decameric 2-Cys peroxiredoxin from human erythrocytes at 1.7 A resolution. Structure 8, 605-615

13. Bolduc, J. A., Nelson, K. J., Haynes, A. C., Lee, J., Reisz, J. A., Graff, A. H., Clodfelter, J. E., Parsonage, D., Poole, L. B., Furdui, C. M., and Lowther, W. T. (2018) Novel hyperoxidation resistance motifs in 2-Cys peroxiredoxins. J. Biol. Chem. 293, 11901-11912

14. Trujillo, M., Clippe, A., Manta, B., Ferrer-Sueta, G., Smeets, A., Declercq, J. P., Knoops, B., and Radi, R. (2007) Pre-steady state kinetic characterization of human peroxiredoxin 5: Taking advantage of Trp84. fluorescence increase upon oxidation. Arch. Biochem. Biophys. 467, 95106

15. Parsonage, D., Nelson, K. J., Ferrer-Sueta, G., Alley, S., Karplus, P. A., Furdui, C. M., and Poole, L. B. (2015) Dissecting peroxiredoxin catalysis: Separating binding, peroxidation, and resolution for a bacterial AhpC. Biochemistry 54, 1567-1575

16. Dalla Rizza, J., Randall, L. M., Santos, J., Ferrer-Sueta, G., and Denicola, A. (2019) Differential parameters between cytosolic 2-Cys peroxiredoxins, PRDX1 and PRDX2. Protein Sci. 28, 191-201

17. Peskin, A. V., Meotti, F. C., De Souza, L. F., Anderson, R. F., and Winterbourn, C. C. (2020) Intra-dimer cooperativity between the active site cysteines during the oxidation of peroxiredoxin 2 Free. Radic. Biol. Med. $158,115-125$

18. Peskin, A. V., Dickerhof, N., Poynton, R. A., Paton, L. N., Pace, P. E., Hampton, M. B., and Winterbourn, C. C. (2013) Hyperoxidation of Peroxiredoxins 2 and 3: Rate constants for the reactions of the sulfenic acid of the peroxidative cysteine. J. Biol. Chem. 288, 14170-14177

19. Williams, C. J., Headd, J. J., Moriarty, N. W., Prisant, M. G., Videau, L. L., Deis, L. N., Verma, V., Keedy, D. A., Hintze, B. J., Chen, V. B., Jain, S., Lewis, S. M., Arendall, W. B., 3rd, Snoeyink, J., Adams, P. D., et al. (2018) MolProbity: More and better reference data for improved all-atom structure validation. Protein Sci. 27, 293-315

20. Eriksson, A. E., Baase, W. A., Zhang, X. J., Heinz, D. W., Blaber, M., Baldwin, E. P., and Matthews, B. W. (1992) Response of a protein structure to cavity-creating mutations and its relation to the hydrophobic effect. Science 255, 178-183

21. Xu, J., Baase, W. A., Baldwin, E., and Matthews, B. W. (1998) The response of T4 lysozyme to large-to-small substitutions within the core and its relation to the hydrophobic effect. Protein Sci. 7, 158-177

22. Parsonage, D., Youngblood, D. S., Sarma, G. N., Wood, Z. A., Karplus, P. A., and Poole, L. B. (2005) Analysis of the link between enzymatic activity and oligomeric state in AhpC, a bacterial peroxiredoxin. Biochemistry 44, 10583-10592

23. Barranco-Medina, S., Kakorin, S., Lazaro, J. J., and Dietz, K. J. (2008) Thermodynamics of the dimer-decamer transition of reduced human and plant 2-cys peroxiredoxin. Biochemistry 47, 7196-7204.
24. Barranco-Medina, S., Lazaro, J. J., and Dietz, K. J. (2009) The oligomeric conformation of peroxiredoxins links redox state to function. FEBS Lett. 583, 1809-1816

25. Pastor-Flores, D., Talwar, D., Pedre, B., and Dick, T. P. (2020) Real-time monitoring of peroxiredoxin oligomerization dynamics in living cells. Proc. Natl. Acad. Sci. U. S. A. 117, 16313-16323

26. Tairum, C. A., Santos, M. C., Breyer, C. A., Geyer, R. R., Nieves, C. J., Portillo-Ledesma, S., Ferrer-Sueta, G., Toledo, J. C., Jr., Toyama, M. H., Augusto, O., Netto, L. E., and de Oliveira, M. A. (2016) Catalytic Thr or Ser residue modulates structural switches in 2-cys peroxiredoxin by distinct mechanisms. Sci. Rep. 6, 33133

27. Loberg, M. A., Hurtig, J. E., Graff, A. H., Allan, K. M., Buchan, J. A., Spencer, M. K., Kelly, J. E., Clodfelter, J. E., Morano, K. A., Lowther, W. T., and West, J. D. (2019) Aromatic residues at the dimer-dimer interface in the peroxiredoxin Tsa1 facilitate decamer formation and biological function. Chem. Res. Toxicol. 32, 474-483

28. Portillo-Ledesma, S., Randall, L. M., Parsonage, D., Dalla Rizza, J., Karplus, P. A., Poole, L. B., Denicola, A., and Ferrer-Sueta, G. (2018) Differential kinetics of two-cysteine peroxiredoxin disulfide formation reveal a novel model for peroxide sensing. Biochemistry 57, 3416-3424.

29. Kriznik, A., Libiad, M., Le Cordier, H., Boukhenouna, S., Toledano, M. B., and Rahuel-Clermont, S. (2020) Dynamics of a key conformational transition in the mechanism of peroxiredoxin sulfinylation. ACS Catal. 10, 3326-3339

30. Nelson, K. J., Parsonage, D., Karplus, P. A., and Poole, L. B. (2013) Evaluating peroxiredoxin sensitivity toward inactivation by peroxide substrates. Methods Enzymol. 527, 21-40

31. Manta, B., Hugo, M., Ortiz, C., Ferrer-Sueta, G., Trujillo, M., and Denicola, A. (2009) The peroxidase and peroxynitrite reductase activity of human erythrocyte peroxiredoxin 2. Arch. Biochem. Biophys. 484, 146-154.

32. Chae, H. Z., Kim, H. J., Kang, S. W., and Rhee, S. G. (1999) Characterization of three isoforms of mammalian peroxiredoxin that reduce peroxides in the presence of thioredoxin. Diabetes Res. Clin. Pract. 45, 101112

33. Nagy, P., Karton, A., Betz, A., Peskin, A. V., Pace, P., O’Reilly, R. J., Hampton, M. B., Radom, L., and Winterbourn, C. C. (2011) Model for the exceptional reactivity of peroxiredoxins 2 and 3 with hydrogen peroxide: A kinetic and computational study. J. Biol. Chem. 286, 18048-18055

34. Pace, P. E., Peskin, A. V., Han, M. H., Hampton, M. B., and Winterbourn, C. C. (2013) Hyperoxidized peroxiredoxin 2 interacts with the protein disulfide- isomerase ERp4.6. Biochem. J. 453, 475-485

35. Peskin, A. V., Low, F. M., Paton, L. N., Maghzal, G. J., Hampton, M. B., and Winterbourn, C. C. (2007) The high reactivity of peroxiredoxin 2 with $\mathrm{H}(2) \mathrm{O}(2)$ is not reflected in its reaction with other oxidants and thiol reagents. J. Biol. Chem. 282, 11885-11892

36. Kabsch, W. (2010) Xds. Acta Crystallogr. D Biol. Crystallogr. 66, 125-132

37. Winn, M. D., Ballard, C. C., Cowtan, K. D., Dodson, E. J., Emsley, P., Evans, P. R., Keegan, R. M., Krissinel, E. B., Leslie, A. G., McCoy, A., McNicholas, S. J., Murshudov, G. N., Pannu, N. S., Potterton, E. A., Powell, H. R., et al. (2011) Overview of the CCP4 suite and current developments. Acta Crystallogr. D Biol. Crystallogr. 67, 235-242

38. Karplus, P. A., and Diederichs, K. (2012) Linking crystallographic model and data quality. Science 336, 1030-1033

39. Liebschner, D., Afonine, P. V., Baker, M. L., Bunkoczi, G., Chen, V. B., Croll, T. I., Hintze, B., Hung, L. W., Jain, S., McCoy, A. J., Moriarty, N. W., Oeffner, R. D., Poon, B. K., Prisant, M. G., Read, R. J., et al. (2019) Macromolecular structure determination using X-rays, neutrons and electrons: Recent developments in Phenix. Acta Crystallogr. D Struct. Biol. 75, 861-877

40. Emsley, P., Lohkamp, B., Scott, W. G., and Cowtan, K. (2010) Features and development of Coot. Acta Crystallogr. D Biol. Crystallogr. 66, 486-501

41. Franke, D., Petoukhov, M. V., Konarev, P. V., Panjkovich, A., Tuukkanen, A., Mertens, H. D. T., Kikhney, A. G., Hajizadeh, N. R., Franklin, J. M., Jeffries, C. M., and Svergun, D. I. (2017) Atsas 2.8: A comprehensive data analysis suite for small-angle scattering from macromolecular solutions. J. Appl. Crystallogr. 50, 1212-1225 
42. Demeler, B. (2005) UltraScan - a comprehensive data analysis software package for analytical ultracentrifugation experiments. In: Scott, D. J., Harding, S. E., Rowe, A. J., eds. Analytical Ultracentrifugation: Techniques and Methods, Royal Society of Chemistry, Cambridge, UK: 210-230

43. Brookes, E., Cao, W. M., and Demeler, B. (2010) A two-dimensional spectrum analysis for sedimentation velocity experiments of mixtures with heterogeneity in molecular weight and shape. Eur. Biophys. J. Biophy. 39, 405-414
44. Demeler, B., and Brookes, E. (2008) Monte Carlo analysis of sedimentation experiments. Colloid Polym. Sci. 286, 129-137

45. Demeler, B., and Gorbet, G. E. (2016) Analytical Untracentrifugation Data Analysis with UltraScan-III, Springer, New York, NY

46. Reisz, J. A., Bechtold, E., King, S. B., Poole, L. B., and Furdui, C. M. (2013) Thiol-blocking electrophiles interfere with labeling and detection of protein sulfenic acids. FEBS J. 280, 6150-6161 


\section{University Library}

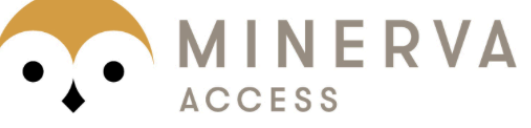

A gateway to Melbourne's research publications

Minerva Access is the Institutional Repository of The University of Melbourne

\section{Author/s:}

Peskin, A;Meotti, FC;Kean, KM;Gobl, C;Peixoto, AS;Pace, PE;Horne, CR; Heath,

SG;Crowther, JM;Dobson, RCJ;Karplus, PA;Winterbourn, CC

Title:

Modifying the resolving cysteine affects the structure and hydrogen peroxide reactivity of peroxiredoxin 2

Date:

2021-01-01

Citation:

Peskin, A., Meotti, F. C., Kean, K. M., Gobl, C., Peixoto, A. S., Pace, P. E., Horne, C. R., Heath, S. G., Crowther, J. M., Dobson, R. C. J., Karplus, P. A. \& Winterbourn, C. C. (2021). Modifying the resolving cysteine affects the structure and hydrogen peroxide reactivity of peroxiredoxin 2. JOURNAL OF BIOLOGICAL CHEMISTRY, 296, https://doi.org/10.1016/ j.jbc.2021.100494.

Persistent Link:

http://hdl.handle.net/11343/278055

License:

CC BY-NC-ND 